\title{
U.S. SAFETY NET PROGRAMS AND EARLY LIFE SKILLS FORMATION: RESULTS FROM A PROSPECTIVE LONGITUDINAL COHORT STUDY
}

\author{
Corneliu Bolbocean \\ Frances A. Tylavsky \\ James E. West \\ Working Paper 24832 \\ http://www.nber.org/papers/w24832 \\ NATIONAL BUREAU OF ECONOMIC RESEARCH \\ 1050 Massachusetts Avenue \\ Cambridge, MA 02138 \\ July 2018
}

The views expressed herein are those of the authors and do not necessarily reflect the views of the National Bureau of Economic Research.

At least one co-author has disclosed a financial relationship of potential relevance for this research. Further information is available online at http://www.nber.org/papers/w24832.ack

NBER working papers are circulated for discussion and comment purposes. They have not been peer-reviewed or been subject to the review by the NBER Board of Directors that accompanies official NBER publications.

(C) 2018 by Corneliu Bolbocean, Frances A. Tylavsky, and James E. West. All rights reserved. Short sections of text, not to exceed two paragraphs, may be quoted without explicit permission provided that full credit, including $(\odot$ notice, is given to the source. 
U.S. Safety Net Programs and Early Life Skills Formation: Results from a Prospective Longitudinal Cohort Study

Corneliu Bolbocean, Frances A. Tylavsky, and James E. West

NBER Working Paper No. 24832

July 2018

JEL No. H5,I1,I38

\section{ABSTRACT}

A large body of literature suggests that the first years of life are critical for long-term economic, health and social outcomes. However, the effect of public programs on early life skills formation is largely unknown due to data limitations. In this paper we use novel data from a large longitudinal prospective cohort study to estimate the effects of WIC, SNAP, and home visitation programs on early life outcomes up to two years of age. We find that participation in these programs has a positive and statistically significant effect on language development and boosts early life noncognitive outcomes.

Corneliu Bolbocean

Department of Economics

Baylor University

One Bear Place \#98003

Waco, TX 76798

corneliu_bolbocean@baylor.edu

Frances A. Tylavsky

University of Tennessee

Health Science Center

462 Doctors Office Building

66 North Pauline St

Memphis, TN 38163

ftylavsky@uthsc.edu
James E. West

Department of Economics

Baylor University

One Bear Place \#98003

Waco, TX 76798

and NBER

j_west@baylor.edu 


\section{Introduction}

Human capital is an essential component of long-term economic growth (Lucas 1988, Romer 1990). Building upon seminal contributions by Schultz (1961) and Becker (1962), Cunha and Heckman (2007) have argued that human capital production and skill formation is a life cycle process that begins in the womb and continues throughout life. An increasingly interdisciplinary body of evidence shows that gaps in skills originating from birth through five years of age establishes a path for lifetime skill formation and long-term economic, health and social outcomes. (Cunha, Heckman, Lochner and Masterov 2006, Hoddinott, Maluccio, Behrman, Flores and Martorell 2008, Cunha, Heckman and Schennach 2010) The economics, psychological and clinical literature offer some guidance in estimating the causal relationships underlying early skills formation; however, the mechanisms of cognitive and noncognitive skill formation outcomes have not been established. A central question of interest is whether skill formation technology depends upon improved nutrition during early childhood. If so, it is conceivable that policymakers can reduce ability gaps between children from various socioeconomic groups and ultimately raise the productivity of society at large through nutrition interventions at an early age.

In this paper, we analyze the effect of the mother's participation in WIC, the Supplemental Nutrition Assistance Program (SNAP) and home visitation on early cognitive and noncognitive developmental outcomes as measured by the Bayley Scales of Infant Development (BSID-III), a set of standardized measures commonly used within the field of developmental science for analyzing short- to medium-term outcomes of babies. (Bayley 2006) ${ }^{1} \mathrm{~A}$ small number of studies in the scholarly literature have been able to carefully identify the causal effect of assistance programs by exploiting the introduction of such programs under experimental or quasi-experimental conditions. (Wydick, Glewwe and Rutledge 2013, Barrera-

\footnotetext{
${ }^{1}$ The BSID-III is a widely accepted developmental assessment instrument for children from birth through 42 months. (Sattler 2008)
} 
Osorio, Bertrand, Linden and Perez-Calle 2011, Behrman, Parker and Todd 2011) Absent an experimental rollout or random assignment into treatment, a suitable instrument for program participation must be found, which has been difficult in practice for food programs. (Bitler and Currie 2005) In our dataset we observe objective measures that determine eligibility into these programs, and other measures that might influence the decision to participate in these programs, such as maternal personality measures (IQ measures, motivation measures, emotional health), maternal knowledge of child development, the child's health status, measures on maternal-child contact and bonding, as well as measures on home and neighborhood environments. To deal with issues of selection, we use mother-infant fixed-effects models, which compare child outcomes over time among mothers who participated in assistance programs and those who did not participate. This technique uses variation in program participation status over time, and controls for unobserved mother-infant pair characteristics and for family and environmental background attributes that are time-invariant.

We find that a mother's participation in WIC during pregnancy and in early childhood has a direct effect on noncognitive skill formation at an early age. We find that WIC increases on average receptive communication z-scores by 0.33 , expressive communication z-scores by 0.15. Our results are robust to the inclusion of a rich set of possible confounding factors. Overall, our results suggest that WIC and the home visitation program improve BSID-III scores and that such programs might have the potential to decrease the gaps in child ability across families of different socioeconomic status. We show that the mothers' participation in the WIC program increases the intake of those nutrients associated with early childhood development such as iron, folic acid, B6 and B12.

Our study is to our knowledge the first to use detailed data on prenatal, perinatal and postneonatal nutritional exposures and developmental outcomes up to two years of age. Our results, which focus on early childhood cognitive and non-cognitive skill formation, builds upon previous research that finds a positive relationship between participation in federal 
nutrition assistance programs and longer term health outcomes. (Hoynes, Schanzenbach and Almond 2016, Currie and Rajani 2015, Hoynes, Page and Stevens 2011). Our discussion of the underlying biological mechanisms by which WIC might affect skills formation further contributes to the literature.

The remainder of our paper is organized as follows. In Section 2, we summarize the economics literature on the long-term effects of early skill formation interventions. In Section 3, we describe our data. In Section 4, we present the conceptual framework and empirical strategy. In Section 5, we present the results. In Section 6, we extend our analysis to examine possible mechanisms. We conclude in Section 7.

\section{Related Literature}

\subsection{Food Assistance Programs}

A number of scholarly papers find evidence that in the United States food and nutrition assistance programs are linked to improved neonatal outcomes (Hoynes et al. 2016, Currie and Rajani 2015, Almond, Hoynes and Schanzenbach 2011, Bitler and Currie 2005) and longterm outcomes. We are only aware of one paper in the health economics literature on the effect of U.S. federal or local food programs on early developmental outcomes. (Bolbocean 2015) In the health research literature, we are aware of two studies that have assessed the direct effect of WIC on the Bayley scales of infant development (Jackson 2015) and on intelligence quotient (IQ) and cognitive test scores in early childhood. (Hicks, Langham and Takenaka 1982) These authors find positive effects of prenatal WIC on cognitive development.

\subsection{Early Skills Formation}

A large body of research shows that skill formation is a highly complex process influenced by environmental, genetic and epigenetic factors in perinatal and postnatal periods. (Haworth 
and Plomin 2010, Stromswold 2006) Understanding the role and related mechanisms of nutritional interventions on early skills formation is critical. The existing scientific literature, using evidence from animal models, demonstrates that early nutrient deficiencies have substantial, long-term negative effects on early brain development. (Georgieff 2007, Meck and Williams 2003, Salvati, Attorri, Avellino, Di Biase and Sanchez 2000) Some nutrients appear to be more important than others for brain development; however, evidence that there are critical and sensitive periods in brain synaptic plasticity is overwhelming. (Heckman 2012) The study of skill formation through the nutritional channel is even more important in human beings because of the dynamic complementarity of the skills formation process. (Cunha et al. 2006) Thus, if a child does not receive appropriate nutrients during early childhood, it might be very difficult or even impossible to appropriately support brain plasticity, (Rosales, Reznick and Zeisel 2009) which ultimately results in poor neurocognitive outcomes at a later age. Better nutrition during childhood is also associated with better health and educational outcomes in children. (Glewwe, Jacoby and King 2001, Winicki and Jemison 2003, Alderman, Hoddinott and Kinsey 2006, Victora, Adair, Fall, Hallal, Martorell, Richter, Sachdev, Maternal, Group et al. 2008) However, there is compelling evidence that the first two years of a child's life are thought to be the critical period when nutrition has the greatest effect on child health, growth and development. (Rosales et al. 2009, Victora et al. 2008)

Evidence on the importance of ability in determining long-term socioeconomic success is overwhelming. Interdisciplinary research has shown the existence of critical and sensitive periods in the formation of skills. (Knudsen 2004) Persistent and substantial gaps in noncognitive and cognitive abilities determine a variety of outcomes and have a direct effect on wages, schooling, teen pregnancies and other socioeconomic outcomes. (Cunha and Heckman 2009) However, early life skill formation is critical because numerous studies in economics and human development have documented that cognitive and noncognitive skills are produced in the early years of childhood. (Cunha and Heckman 2007, Cunha et 
al. 2010, Heckman, Stixrud and Urzua 2006, Christopher Auld and Sidhu 2005, Carneiro, Heckman and Masterov 2005)

Existing research shows that the technology of skill formation is both self-productive ${ }^{2}$ and complementary $^{3}$, as skills beget skills in a complementary and dynamic way. (Cunha and Heckman 2007) However, complementarity and self-productivity implies no equity-efficiency trade-off for early investments, (Cunha and Heckman 2007) and that returns to later childhood investment are low. If a child does not receive the appropriate stimulation during early childhood, it might be very difficult to later develop functions associated with improved socioeconomic outcomes.

\subsection{Nutrition and Early Skills Formation}

The fetal, neonatal and postnatal period is a time of rapid brain development (neuroplasticity), and of critical acquisition of cognitive development and interpersonal skills. (Kochanska, Coy and Murray 2001, Bouchard-Mercier, Paradis, Rudkowska, Lemieux, Couture and Vohl 2013) Evidence that nutrition is a direct biological and mediating factor in brain growth and development is abundant in the scientific literature. A range of in vitro human and animal models have been used to characterize the mechanistic linkages between nutritional deficiencies, and structural or functional alterations in neurodevelopment and impact on behavior. (Georgieff 2007) More recently, the epigenetic effects of nutrients are documented in the emergent genetics literature.

Extensive epidemiological, economics and health sciences researchers have explored the role of nutrition in early childhood and the relationship to health outcomes in adulthood. Given the fundamental role of nutrients in supporting all aspects of structural and functional brain development, food assistance programs provide essential nutrients that must be introduced by diet because they cannot be synthesized by the organism. Lack of nutrition

\footnotetext{
${ }^{2}$ Self-productivity implies that the formation of skills has a higher return if baseline skills are higher.

${ }^{3}$ Complementarity implies that early investment facilitates the productivity of later investment
} 
has a negative influence on all aspects of development and can lead to adaptive physiological responses that impair development with long-term consequences. (Bhutta 2008)

With a combined spending of $\$ 82.85$ billion per year, (USDA 2017b, USDA 2017a) WIC and SNAP are the two fundamental safety net programs funded by the U.S. federal government. As an entitlement program, SNAP is available to all income-eligible families and was rolled out between 1962 and 1975, providing low-income families with vouchers that can be used at grocery stores to purchase food. WIC aims to increase nutritional well-being among low-income pregnant and postpartum women, infants and young children. Established in 1972, the program offers three types free-of-charge benefits to participants: a supplemental food package, nutrition education, and referrals to health care and other services. These packages include combinations of the following foods: iron-fortified infant formula, ironfortified infant and adult cereal, vitamin C-rich fruit juice and/or vegetable juice, eggs, milk, cheese, peanut butter and/or dried beans or peas, tuna and carrots. Special infant formulas and certain medical foods could also be provided by the WIC food package when prescribed by a physician or health professional for a specific medical condition. Existing research links participation in SNAP or WIC to health outcomes. The literature has focused on critical birth outcomes, such as low birth weight, preterm delivery and infant mortality. (Hoynes et al. 2011, Bitler and Currie 2005, Hoynes et al. 2016, Bitler, Currie and Scholz 2003)

Much of the research on WIC's effect on participants' health faces a number of methodological challenges, in addition to issues of selection bias. Many outcomes develop over a long period and require controlling for the complex interplay of diet and environment. Furthermore, economic theory suggests that relationships between federal and local programs, and associated eligibility criteria would induce individuals to optimize decisions related to participation in different programs. For example, a majority of WIC participants also use other assistance programs, such as Medicaid and SNAP. Moreover, the impact of local food programs on health or developmental outcomes is largely unknown. This requires identifying 
whether the observed effect is due to WIC, SNAP, or to another program.

\subsection{Home Visitation Programs and Early Skills Formation}

Home visitation programs have been administered by the Tennessee Department of Health since 1979. Approximately 3,700 families have received services from one of the evidencebased, research-based or "promising approach" home visiting programs during the period of July 1, 2013 through June 30, 2014. Each of the programs has different enrollment criteria and models of service delivery, which results in different outcomes for participants. All programs support families with young children by frequently visiting them in their home (weekly, bi-weekly or monthly) over a substantial length of time (1-5 years). Impacts found include improved immunization status of children, decreased child abuse and neglect, increased breastfeeding initiation, decreased smoking by mothers, increased screening of child development, and delayed subsequent pregnancies by mothers receiving services. (TDH 2014)

\section{Data}

For this study, we use data from the Conditions Affecting Neurocognitive Development and Learning in Early Childhood study (CANDLE). CANDLE is a prospective longitudinal study of early cognitive development that extends from the second trimester of pregnancy until the child reaches four years of age. (Sontag-Padilla, Burns, Shih, Martin, Tylavsky and Chandra 2016) The main goal of the CANDLE study was to investigate the separate and combined effects of a mother's prenatal experiences, a child's home environment and experiences, exposure to potentially harmful toxins, and genetic makeup on the child's brain development from birth to three years of age. We describe the features of CANDLE and provide the CANDLE data collection timeline in Appendix A.

Table 1 provides an overview of our data. In the full sample, $62 \%$ of the mothers were 
African American, $48 \%$ of mothers were on Medicaid (TennCare) insurance, $47 \%$ with annual reported income less than $\$ 24,999,47 \%$ married, $9 \%$ reported tobacco use and $49 \%$ had a high school diploma. Fifty percent of mothers reported participation in WIC and $44 \%$ participation in SNAP; however, uptake in WIC declined over time much more than in SNAP. In particular, second home visit participation in SNAP was virtually unchanged while only $28 \%$ of women participated in WIC. Very few mothers reported uptake in local food assistance programs during pregnancy (around 1\%); however, enrollment in home visitation programs was reported by $6 \%$ during pregnancy. The cohort had an average Apgar score of 9 at 5 minutes, and an average gestational age of 39 weeks. Consistent with findings from previous literature, children born to mothers enrolled in federal assistance programs were more likely to be low birth weight, to have low Apgar scores small for date. (Hoynes et al. 2016, Hoynes et al. 2011) Consistent with Currie and Rajani's (2015) observations, we find that mothers of WIC infants were younger, less likely to be married, much less educated, and more likely to smoke. They also were more likely to have complications of labor and delivery as well as more likely to be on Medicaid.

\subsection{Outcome Data}

Evaluation of neurodevelopmental dysfunction or delay is a central aspect of developmental psychology. The literature on standardized, developmental screening measures and associated instruments, particularly in the care of at-risk populations, is vast. (Johnson, Gliga, Jones and Charman 2015, Woods, Rieger, Wocadlo and Gordon 2014, Visser, Ruiter, Van der Meulen, Ruijssenaars and Timmerman 2013) Overall, the field of developmental psychology and clinical pediatrics require that these instruments should have good concurrent and predictive properties and be readily employed in clinical settings or large studies where highly detailed assessment is not feasible.

We chose the Bayley Scales of Infant Development, which is a standard measure for an- 
alyzing short- to medium-term outcomes of babies and is commonly used within the field of developmental science for children ages birth to 42 months. (Sattler 2008). BSID-III was designed to identify possible developmental delay in infants, inform health professionals about areas of strength or weakness when planning an intervention, and monitor the progression of the child's development. (Albers and Grieve 2007) It is based on assumptions of a model of general intelligence that assumes that the more rapid attainment of such milestones reflects higher intellectual ability. (Colombo 1993)

The BSID-III consists of five scales (cognitive, language, motor, social-emotional, and adaptive behavior) that assess areas of development for children from birth to three years of age. The CANDLE study used only the cognitive and language scales. The cognitive scale consists of 91 items. The language scale contains 97 items from the receptive (49 items) and expressive communication (48 items) subtests that are designed to provide information about a child's ability to understand and respond to verbal stimuli, to name pictures and objects, and to communicate with others. (Albers and Grieve 2007)

To assess children's cognitive outcomes at year one and year two, we use the Bayley-III. (Bayley 2006) The Bayley-III includes items psychometrically selected from the more comprehensive BSID. (Bayley 2006) Internal consistency and test-retest reliability coefficients of the Bayley-III for infants' cognitive, receptive communication and expressive communication subtests are high to very high, (Nunnally 1994) ranging from 0.76 to 0.93. (Bayley 2006) The validity of the Bayley-III, examined by determining its classification accuracy with the BSID-III scaled scores, showed correlations between the Bayley-III cognitive, receptive communication and expressive communication subtests and the BSID-III comprehensive scales of $0.93,0.95$ and 0.95 , respectively. (Bayley 2006)

Although the Bayley-III has five subtests, we selected the cognitive (nonverbal), receptive communication and expressive communication subtests as phenotypic outcomes in this study. (Bayley 2006) We chose these subtests because of their content similarity with other 
measures of cognitive development used later in childhood. Subtest scores are used to determine whether the child's scoring is in the lowest risk or competent category, the emerging risk category, or the at-risk category. At 1 year of age, the Bayley-III cognitive items focus primarily on short-term visual memory, functional play and nonverbal problem-solving. Receptive communication items include pointing to common objects or pictures of actions in a picture book, as well as responding to commands, while expressive communication items quantify emitted sound and sound combinations at 1 year of age.

A rigorous training was established to maintain Bayley-III reliability. After graduate coursework in preschool assessment and child development, the cognitive examiners attended didactic instruction on the Bayley-III. Inter-rater reliability attained through direct observation of test administration and scoring yielded reliability coefficients equal to or greater than 0.90 on all subtests. A summary of cognitive, receptive communication and expressive communication tests for each year can be found in Table 2 .

We provide a brief overview of the types of data used in our analysis to capture relevant information about a mother's and child's psychosocial measures in Appendix B.

\section{Conceptual Framework and Empirical Strategy}

Consistent with models of skill formation, we model multiple dimensions of child skills (cognitive, noncognitive) over a discrete and finite period. The production of cognitive and noncognitive skills acquisition is a cumulative process, which means that past and current inputs are combined with a child's endowment (genetic) to produce a specific type of skills.

We use a cumulative specification of skills formation with an endowment which is assumed orthogonal to omitted inputs. (Todd and Wolpin 2007) Let $T_{i j a}$ be the Bayley-III test score measure of child $i$ residing in household $j$ at age $a$. Consistent with the existing literature, we assume that the production of $T_{i j a}$ is approximately linear in participation in WIC, as indicated by $D_{i a}$,other explanatory variables $X_{i j a}$, and contains an unobserved endowment 
$\mu_{i j}^{0}$ with input effects being time-invariant. In particular,

$$
T_{i j a}=D_{i a} \alpha+\mu_{i j}^{0}+\sum_{k=0}^{a-1} X_{i j a-k} \beta_{k}+\varepsilon_{i j a}
$$

where $\varepsilon_{i j a}$ is the stochastic error term that includes the effect of any omitted inputs and measurement error.

Our data contain repeated observations on cognitive and noncognitive outcomes and on inputs for a given child at different ages. Because of this, we are able to calculate a first difference in the test score, which structurally becomes

$$
\Delta T_{i j a}=\Delta D_{i a} \alpha+\sum_{k=0}^{a-2} \Delta X_{i j a-k} \beta_{k}+X_{i j 1} \beta_{a-1}+\Delta \varepsilon_{i j a}
$$

As a result of differencing, any time-invariant input is eliminated from our model to be estimated, including child $i$ 's unobserved skill endowment.

Previous studies have found that mothers who receive WIC during pregnancy tend to be less educated, more likely to be of a minority race, less likely to be married and more likely to be teen mothers. (Bitler and Currie 2005, Knudsen 2004). The subset of these maternal characteristics which are time-invariant are also eliminated by differencing. However, time-varying maternal characteristics which affect participation in WIC or childhood skills development must be included in (3) to ensure consistent estimates.

To control for selection effects regarding program participation we use objective eligibility requirements for WIC, SNAP and home visiting programs and previously unavailable measures that might influence the decision to participate in these programs. For WIC and SNAP we observe both income and family size; additionally we observed whether the mother was on Temporary Assistance for Needy Families, or TennCare Medicaid, which automatically qualifies the mother to receive WIC benefits. Shelby County home visitation programs serve first-time mothers, teen mothers and low-income mothers, and participation is voluntary. 
The decision to participate might also be driven by non-objective eligibility criteria. For example, one can argue that a more knowledgeable, caring, or loving mother is more likely to participate in these programs. Also, fetal or child health is another factor that might drive the decision to seek help, or be referred to participate in these programs. We thus control for possible selection effects using the following time-varying covariates: maternal personality measures (IQ measures, motivation measures, emotional health), maternal knowledge of child development, child's health status, measures on maternal-child contact and bonding, as well as measures on home and neighborhood environments and others.

Our basic model contains the following time-varying $X_{i t}$ covariates: child characteristics (weight, developmental concerns, hospitalizations), maternal and household characteristics (employment status, presence of a romantic partner, marital status, knowledge of infant development, participation in SNAP program, participation in home visitation program), child's environment (quality of neighborhood index, crime index). We added a richer timevarying covariate set in robustness checks. We estimate our specifications over the full sample and each of the following subsamples: Medicaid participants, income-eligible mothers, mothers who reported WIC uptake during pregnancy and African-American mothers.

\subsection{Selection}

CANDLE participants, when asked about their participation status in WIC, SNAP, and home visitation programs, can report one of four possibilities: The mother participated in both years, the mother did not participate in either year, the mother participated in year 1 but not year 2, or the mother participated in year 2 but not year 1 . Prior to more formal tests for selection, we present disaggregated summary statistics for maternal characteristics by program particiaptioin status in Tables 3 and 4. We report first year maternal characteristics disaggregated by participation status in Table 3, and second year maternal characteristics in Table 4. Columns 2-5 in both tables disaggregate by WIC participation status, columns 
6-9 disaggregate by SNAP participation status, and columns 10-13 disaggregate by home participation program status.

Our specification can identify the coefficient of interest from equation (2), $\alpha$, the effect of changing participation in WIC, SNAP, or the home visitation program on skills formation, only for mothers who change participation status, or switchers. Because of this, we analyze only participants recorded in the final two columns of each group in Tables 3 and 4, mothers who participate in year 1 but not in year 2, and mothers who participate in year 2 but not in year 1 . Our estimates of $\alpha$ consistently measure the benefits of program participation to the extent that mothers who participate in both years, and one year but not the other, are similar. To more formally assess the extent to which selection may be present, we present in Table 5 estimates of whether first year participation (but not second year) is a function of various first period maternal statistical controls. In Table 6, we estimate whether participation in the second year (but not the first) is a function of second year maternal characteristics. In both Table 5 and 6 , the only estimated coefficient that was significant above a marginal level was the effect of income on participation in SNAP. Income has a negative effect significant at the $5 \%$ level. Since the SNAP program is designed to supplement low income households, this finding is not surprising. Across all other covariates, estimated coefficients are at most marginally significant. We conclude that the two types of switchers are largely comparable. 4

\section{Results}

To illustrate the extent of selection problems into nutrition supplement and home visitation programs, we estimate BSID-III scores from our data in the first and second years as a

\footnotetext{
${ }^{4}$ We ran additional selection regressions not reported in which selection type was estimated as a function of the following child-based covariates: sex, Nursing Child Assessment Parent-Child Interaction Teaching Scale, evaluation by any health provider for any reason, illness not requiring a visit to a MD, Emotional Stability Score, Child Abuse Potential Inventory Loneliness Total Score, Behavior Problems Total Score, and Child Abuse Potential Inventory Happiness Total Score. We were unable to find any significant correlations.
} 
function of participation in WIC, SNAP, and the home visitation program. The estimated coefficients are presented in Table 7. Specifications (1) and (4) are simple OLS regressions without any additional explanatory variables beyond the three shown. Specifications (2) and (5) include participation in Medicaid and a variety of demographic variables. Specifications (3) and (6) add a variety of control variables which include knowledge of infant development and a variety of psychological and behavioral health outcomes. Coefficients which estimate the effect of WIC, SNAP, and home visitation programs on standardized BSID-III measures of aggregate development, receptive communication, cognitive skills, and expressive communication are all negative if significant at any level. Coefficient magnitudes are as high as -0.493, indicating that the second year aggregate development scores of WIC participants are 0.493 standard deviations less than that of non-participants. These estimates should not be viewed as an estimate of the effect of program participation, as it does not correct for the unobserved initial skills endowment, $\mu_{i j}^{0}$ from equation (1).

To correct for the initial skills endowment, we estimate the change in skills test scores as specified in equation (2). Estimated coefficients are in Table 8. We find that participation in WIC, SNAP and home visitation programs has a positive and significant effect on standardized BSID-III scores measuring aggregate development, receptive communication, cognitive skills, and expressive communication. This effect persists when estimating the effects of these programs jointly, and with both sets of additional control variables. We find that participation in WIC most reliably affects BSID-III receptive communication across all specifications. Magnitudes range from 0.209 to 0.346 standard deviations, all significant at the $1 \%$ level. The effect of SNAP participation is smaller in magnitude than for WIC, but has a positive and highly significant effect on all four measured categories, all at the $1 \%$ level. Interestingly, we found statistically significant effects of neighborhood quality on all BSID-III scores, maternal knowledge of infant development (on receptive and expressive communication scores), developmental concerns and hospitalizations (on expressive communication scores only). 
We next repeat our Specification (6) of Table 8 which uses the most comprehensive set of controls, and iteratively add additional control variables. Table 9 presents the estimated marginal effect of participation in WIC on the indicated skills measurement as additional control variables are added. From Table 8, Specification (6), Panel A, The effect of participation in WIC on aggregate development scores is 0.168 and significant at the $10 \%$ level. In the first row of the first column of Table 9, as Parent-Child Interaction is controlled for, the estimated effect of WIC on the change in aggregate development becomes larger, 0.20, and increases in significance to the $5 \%$ level. As additional explanatory variables are added, the magnitude and significance of the effect of WIC remains very stable. This pattern is repeated for cognitive scores, receptive communication, and expressive communication scores. We interpret this as further evidence of the strength and robustness of the effect of WIC on aggregate scores.

\section{Extensions}

\subsection{WIC, Food Choices, and Critical Nutrients}

Having found robust evidence that exposure to WIC during early life improves children's skills formation, we further explore the potential mechanisms of WIC. As shown in section 2.2 , critical nutrients shape biological formation of the skills formation process. We sought to understand whether the WIC program increases the intake of foods rich in animal protein and critical nutrients for fetal and early childhood development. To achieve this, we plot kernel distributions, run median and Mann-Whitney tests for equality of means as well as the Kolmogorov-Smirnov test for equality of distributions between WIC and non-WIC participants for the following foods and nutrients: beef, pork, lamb, lean meat, eggs, fish seafood high in Omega-3, fish seafood low in omega-3, folic acid (mg), iron (mg), vitamin B-12(mg) and vitamin B-6(mg). In each of the plots, the distribution of nutrient intake for 
WIC participants appears to right dominate the distribution of non-participants. Likewise, the median and Mann-Whitney tests reject the null hypothesis that the mean foods and nutrients between WIC and non-WIC participants are equal, and the Kolmogorov-Smirnov test rejects the null hypothesis of common distribution of foods and nutrients for WIC and non-WIC participants (Table 10). We conclude there is significant evidence that the intake of foods rich in animal protein and critical nutrients is higher among WIC participating mothers.

\section{Conclusions}

In this paper, we estimate the effect of mothers' participation in WIC, SNAP and home visitation programs on early childhood skills development as measured by the BSID-III. We are able to identify the effect of these programs on neurodevelopmental outcomes and credibly control for selection effects related to program participation through the use of timevarying maternal and child characteristics. We find that maternal participation in WIC in early childhood has a direct effect on language development, the effect of SNAP and home visitation program are much smaller in magnitude. Our results are robust to the inclusion of a rich set of possible time-varying confounding factors. Overall, our results suggest that WIC and home visitation programs improve BSID-III scores and that such programs have the ability to decrease gaps in child ability across families of different socioeconomic statuses.

An important limitation of this paper is that we have no way to assess the generalizability of our findings beyond our studied population of the children of Memphis, TN. An additional limitation is that the statistical methods we use are second-best methods which may not fully control for selection effects. This is true of all comparable studies, as the ideal methodology, a prospective randomized controlled trial (RCT), is unlikely to ever be implemented due to pragmatic considerations and concerns. 


\section{References}

Albers, Craig A, and Adam J Grieve (2007) 'Test review: Bayley, n.(2006). bayley scales of infant and toddler development-third edition. san antonio, tx: Harcourt assessment.' Journal of Psychoeducational Assessment 25(2), 180-190

Alderman, Harold, John Hoddinott, and Bill Kinsey (2006) 'Long term consequences of early childhood malnutrition.' Oxford economic papers 58(3), 450-474

Almond, Douglas, Hilary W Hoynes, and Diane Whitmore Schanzenbach (2011) 'Inside the war on poverty: The impact of food stamps on birth outcomes.' The Review of Economics and Statistics 93(2), 387-403

Barnard, K, S Eyres, M Lobo, and C Snyder (1983) 'An ecological paradigm for assessment and intervention.' New approaches to developmental screening of infants pp. 199-218

Barrera-Osorio, Felipe, Marianne Bertrand, Leigh L. Linden, and Francisco Perez-Calle (2011) 'Improving the design of conditional transfer programs: Evidence from a randomized education experiment in colombia.' American Economic Journal.Applied Economics 3(2), 167-195

Bayley, N (2006) Bayley scales of infant and toddler development (Pearson Education, Inc)

Becker, Gary S (1962) 'Investment in human capital: A theoretical analysis.' Journal of political economy 70(5, Part 2), 9-49

Behrman, Jere R, Susan W Parker, and Petra E Todd (2011) 'Do conditional cash transfers for schooling generate lasting benefits? a five-year followup of progresa/oportunidades.' Journal of Human Resources 46(1), 93-122

Bhutta, Zulfiqar A (2008) 'Micronutrient needs of malnourished children.' Current Opinion in Clinical Nutrition $\&$ Metabolic Care 11(3), 309-314 
Bitler, Marianne P, and Janet Currie (2005) 'Does wic work? the effects of wic on pregnancy and birth outcomes.' Journal of Policy Analysis and Management 24(1), 73-91

Bitler, Marianne P, Janet Currie, and John Karl Scholz (2003) 'Wic eligibility and participation.' Journal of Human resources pp. 1139-1179

Bolbocean, Corneliu (2015) 'Early life environments and long term outcomes.' PhD dissertation, Arts \& Social Sciences:

Bouchard-Mercier, Annie, Ann-Marie Paradis, Iwona Rudkowska, Simone Lemieux, Patrick Couture, and Marie-Claude Vohl (2013) 'Associations between dietary patterns and gene expression profiles of healthy men and women: a cross-sectional study.' Nutrition journal 12(1), 24

Briggs-Gowan, Margaret J, Alice S Carter, Julia R Irwin, Karen Wachtel, and Domenic V Cicchetti (2004) 'The brief infant-toddler social and emotional assessment: screening for social-emotional problems and delays in competence.' Journal of pediatric psychology $29(2), 143-155$

Briggs-Gowan, Margaret J, and Alice S Carter (2008) 'Social-emotional screening status in early childhood predicts elementary school outcomes.' Pediatrics 121(5), 957-962

Carneiro, Pedro, James J Heckman, and Dimitriy V Masterov (2005) 'Labor market discrimination and racial differences in premarket factors.' The Journal of Law and Economics $48(1), 1-39$

Christopher Auld, M, and Nirmal Sidhu (2005) 'Schooling, cognitive ability and health.' Health economics 14(10), 1019-1034

Colombo, J (1993) Infant Cognition: Predicting Later Intellectual Functioning (SAGE Publications) 
Cunha, Flavio, and James Heckman (2007) 'The technology of skill formation.' Technical Report, National Bureau of Economic Research

Cunha, Flavio, and James J Heckman (2009) 'The economics and psychology of inequality and human development.' Journal of the European Economic Association 7(2-3), 320364

Cunha, Flavio, James J Heckman, and Susanne M Schennach (2010) 'Estimating the technology of cognitive and noncognitive skill formation.' Econometrica 78(3), 883-931

Cunha, Flavio, James J Heckman, Lance Lochner, and Dimitriy V Masterov (2006) 'Interpreting the evidence on life cycle skill formation.' Handbook of the Economics of Education 1, 697-812

Currie, Janet, and Ishita Rajani (2015) 'Within-mother estimates of the effects of wic on birth outcomes in new york city.' Economic inquiry 53(4), 1691-1701

Georgieff, Michael K (2007) 'Nutrition and the developing brain: nutrient priorities and measurement.' The American journal of clinical nutrition 85(2), 614S-620S

Glewwe, Paul, Hanan G Jacoby, and Elizabeth M King (2001) 'Early childhood nutrition and academic achievement: a longitudinal analysis.' Journal of public economics 81(3), 345368

Haworth, Claire MA, and Robert Plomin (2010) 'Quantitative genetics in the era of molecular genetics: Learning abilities and disabilities as an example.' Journal of the American Academy of Child $\mathscr{G}$ Adolescent Psychiatry 49(8), 783-793

Heckman, James J (2012) 'Invest in early childhood development: Reduce deficits, strengthen the economy.' The Heckman Equation 
Heckman, James J, Jora Stixrud, and Sergio Urzua (2006) 'The effects of cognitive and noncognitive abilities on labor market outcomes and social behavior.' Journal of Labor economics 24(3), 411-482

Hicks, Lou E, Rose A Langham, and Jean Takenaka (1982) 'Cognitive and health measures following early nutritional supplementation: a sibling study.' American Journal of Public Health 72(10), 1110-1118

Hoddinott, John, John A Maluccio, Jere R Behrman, Rafael Flores, and Reynaldo Martorell (2008) 'Effect of a nutrition intervention during early childhood on economic productivity in guatemalan adults.' The lancet 371(9610), 411-416

Horodynski, Mildred A, and Cynthia Gibbons (2004) 'Rural low-income mothers' interactions with their young children.' Pediatric Nursing 30(4), 299

Hoynes, Hilary, Diane Whitmore Schanzenbach, and Douglas Almond (2016) 'Long-run impacts of childhood access to the safety net.' The American Economic Review 106(4), 903-934

Hoynes, Hilary, Marianne Page, and Ann Huff Stevens (2011) 'Can targeted transfers improve birth outcomes?: Evidence from the introduction of the wic program.' Journal of Public Economics 95(7-8), 813-827

Jackson, Margot I (2015) 'Early childhood wic participation, cognitive development and academic achievement.' Social Science \&3 Medicine 126, 145-153

Johnson, Mark H, Teodora Gliga, Emily Jones, and Tony Charman (2015) 'Annual research review: Infant development, autism, and adhd-early pathways to emerging disorders.' Journal of Child Psychology and Psychiatry 56(3), 228-247

Karabekiroglu, Koray, Margaret J Briggs-Gowan, Alice S Carter, Ayse Rodopman-Arman, and Seher Akbas (2010) 'The clinical validity and reliability of the brief infant-toddler 
social and emotional assessment (bitsea).' Infant Behavior and Development 33(4), 503509

Knudsen, Eric I (2004) 'Sensitive periods in the development of the brain and behavior.' Journal of cognitive neuroscience 16(8), 1412-1425

Kochanska, Grazyna, Katherine C Coy, and Kathleen T Murray (2001) 'The development of self-regulation in the first four years of life.' Child development 72(4), 1091-1111

Lucas, Robert E (1988) 'On the mechanics of economic development.' Journal of monetary economics 22(1), 3-42

MacPhee, David (1981) 'Manual: Knowledge of infant development inventory.' Unpublished manuscript, University of North Carolina

Meck, Warren H, and Christina L Williams (2003) 'Metabolic imprinting of choline by its availability during gestation: implications for memory and attentional processing across the lifespan.' Neuroscience \& Biobehavioral Reviews 27(4), 385-399

Milner, Joel S (1986) The child abuse potential inventory: Manual (Psytec)

Milner, Joel S, and Julie L Crouch (2012) 'Psychometric characteristics of translated versions of the child abuse potential inventory.' Psychology of Violence 2(3), 239

Nunnally, JC (1994) Psychometric theory (McGraw-Hill, Inc)

Pridham, Karen A, Kristin F Lutz, Lori S Anderson, Susan K Riesch, and Patricia T Becker (2010) 'Furthering the understanding of parent-child relationships: A nursing scholarship review series. part 3: Interaction and the parent-child relationship-assessment and intervention studies.' Journal for Specialists in Pediatric Nursing 15(1), 33-61

Romer, Paul M (1990) 'Endogenous technological change.' Journal of political Economy 98(5, Part 2), S71-S102 
Rosales, Francisco J, J Steven Reznick, and Steven H Zeisel (2009) 'Understanding the role of nutrition in the brain and behavioral development of toddlers and preschool children: identifying and addressing methodological barriers.' Nutritional neuroscience 12(5), 190-202

Salvati, S, L Attorri, C Avellino, A Di Biase, and M Sanchez (2000) 'Diet, lipids and brain development.' Developmental neuroscience 22(5-6), 481-487

Sattler, J (2008) Assessment of children: cognitive foundations (Jerome M. Sattler Publisher, Inc)

Schultz, Theodore W (1961) 'Investment in human capital.' The American economic review $51(1), 1-17$

Sontag-Padilla, Lisa M, Rachel M Burns, Regina A Shih, Laurie T Martin, Frances Tylavsky, and Anita Chandra (2016) The Urban Child Institute CANDLE study: Methodological overview and baseline sample description (Rand Corporation)

Stromswold, Karin (2006) 'Why aren't identical twins linguistically identical? genetic, prenatal and postnatal factors.' Cognition 101(2), 333-384

Sumner, Georgina A, and Anita Spietz (1996) NCAST caregiver/parent-child interaction teaching manual (NCAST Publications)

\section{TDH (2014) 'ANNUAL HOME VISITING REPORT'}

Todd, Petra E, and Kenneth I Wolpin (2007) 'The production of cognitive achievement in children: Home, school, and racial test score gaps.' Journal of Human capital 1(1), 91136

USDA (2017a) 'SNAP'

(2017b) 'WIC' 
Veddovi, Marina, Dianna T Kenny, Frances Gibson, Jennifer Bowen, and D Starte (2001) 'The relationship between depressive symptoms following premature birth, mothers' coping style, and knowledge of infant development.' Journal of reproductive and infant psychology 19(4), 313-323

Victora, Cesar G, Linda Adair, Caroline Fall, Pedro C Hallal, Reynaldo Martorell, Linda Richter, Harshpal Singh Sachdev, Maternal, Child Undernutrition Study Group et al. (2008) 'Maternal and child undernutrition: consequences for adult health and human capital.' The lancet 371(9609), 340-357

Visser, Linda, Selma AJ Ruiter, Bieuwe F Van der Meulen, Wied AJJM Ruijssenaars, and Marieke E Timmerman (2013) 'Validity and suitability of the bayley-iii low motor/vision version: A comparative study among young children with and without motor and/or visual impairments.' Research in developmental disabilities 34(11), 3736-3745

Winicki, Joshua, and Kyle Jemison (2003) 'Food insecurity and hunger in the kindergarten classroom: its effect on learning and growth.' Contemporary economic policy 21(2), 145157

Woods, Patricia L, Ingrid Rieger, Crista Wocadlo, and Adrienne Gordon (2014) 'Predicting the outcome of specific language impairment at five years of age through early developmental assessment in preterm infants.' Early human development 90(10), 613-619

Wydick, Bruce, Paul Glewwe, and Laine Rutledge (2013) 'Does international child sponsorship work? a six-country study of impacts on adult life outcomes.' Journal of Political Economy 121(2), 393-436 


\section{First set of graphs}
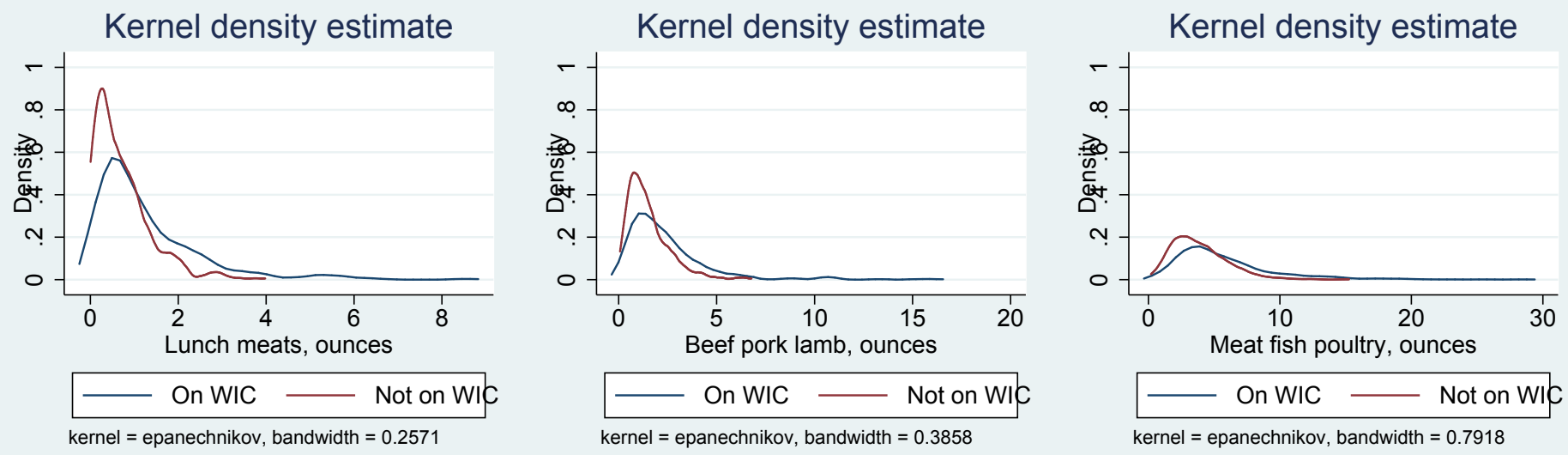

\section{Second set of graphs}
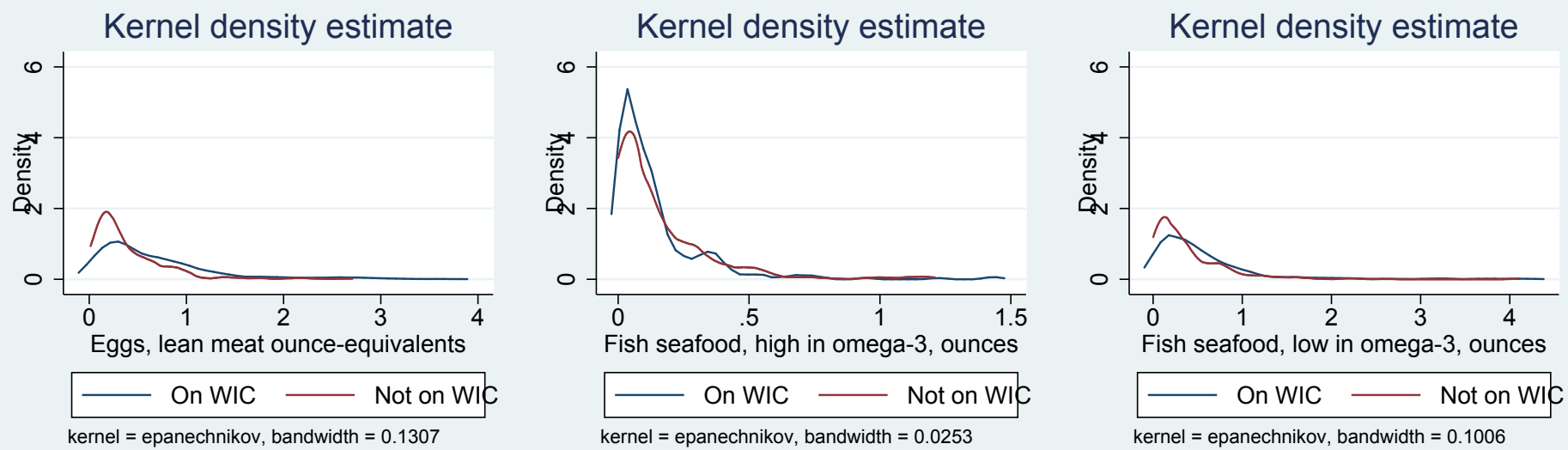


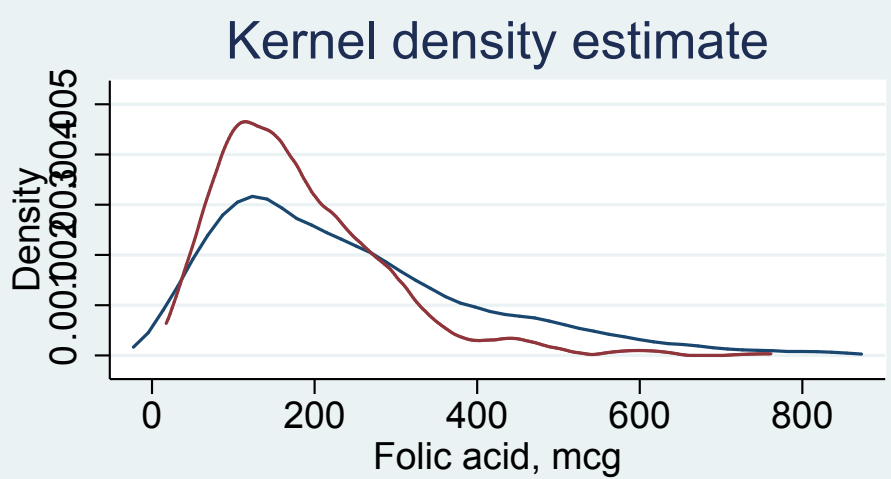

On WIC

kernel $=$ epanechnikov, bandwidth $=40.6526$

Kernel density estimate

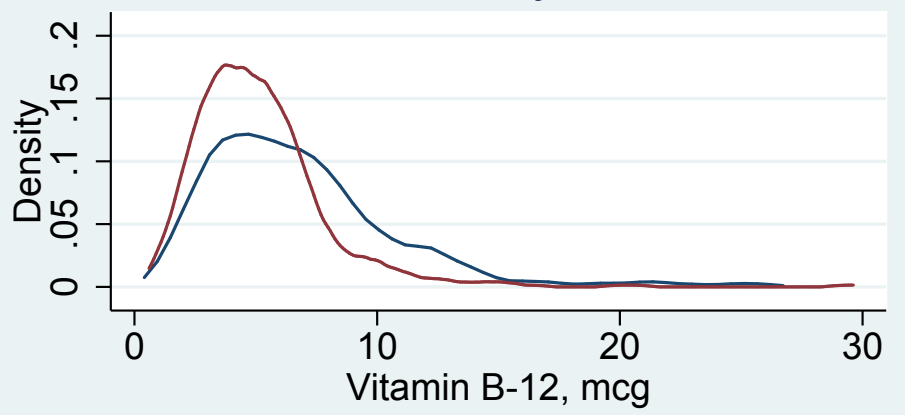

On WIC $\longrightarrow$ Not on WIC

kernel $=$ epanechnikov, bandwidth $=0.8726$

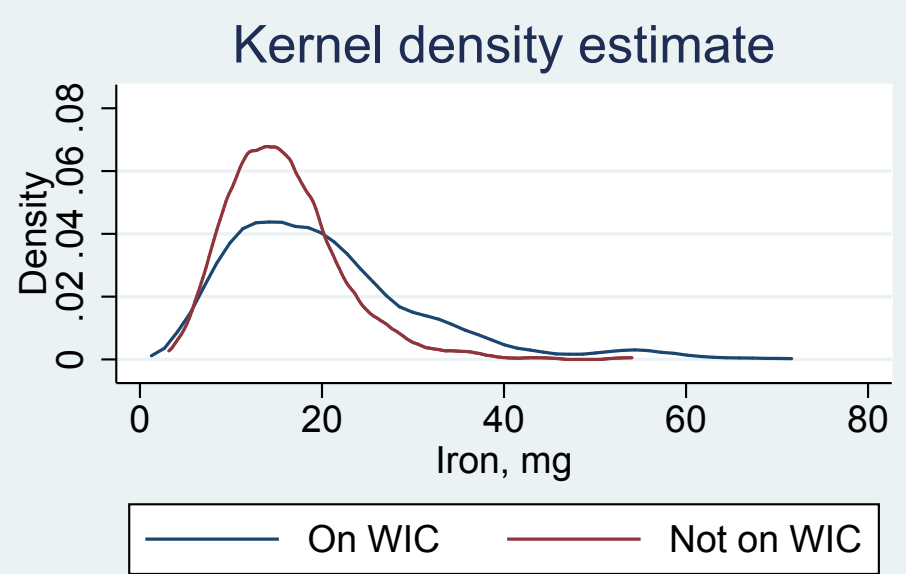

kernel = epanechnikov, bandwidth $=2.5573$

Kernel density estimate

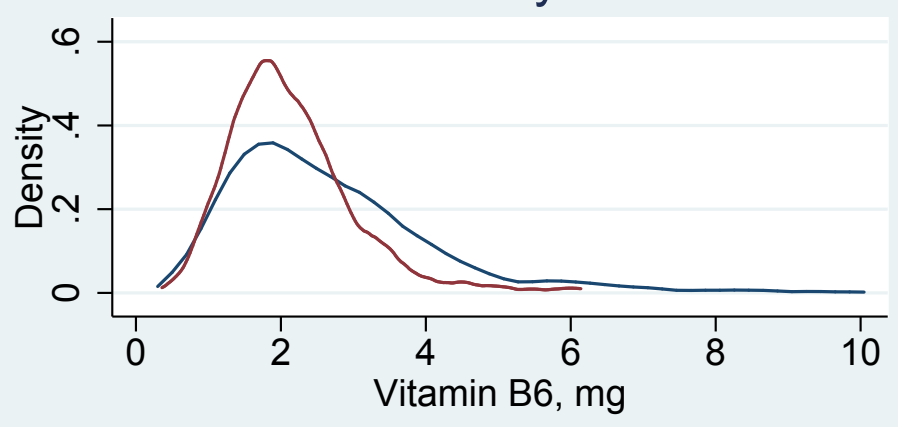

On WIC

Not on WIC 
Table 1: Demographics of CANDLE Participants and Shelby County, TN

\begin{tabular}{lcc}
\hline & $\begin{array}{c}(1) \\
\text { CANDLE } \\
\text { Participants } \\
\text { mean }\end{array}$ & $\begin{array}{c}(2) \\
\text { VARIABLES } \\
\text { Tract } \\
\text { mean }\end{array}$ \\
\hline African-American & & \\
Caucasian & 0.66 & 0.60 \\
Unmarried & 0.31 & 0.27 \\
Less than High School & 0.63 & 0.61 \\
High School Graduate & 0.12 & 0.13 \\
Completed Bachelor's Degree or More & 0.56 & 0.57 \\
Income $<\$ 35,000$ & 0.31 & 0.30 \\
$\$ 35,000 \leq$ Income i $\$ 75,000$ & 0.58 & \\
$\$ 75,000 \leq$ Income & 0.18 & \\
Unreported Income & 0.15 & \\
Median Household Income & 0.09 & \\
Per Capita Annual Income & & $\$ 46,854$ \\
\hline
\end{tabular}


Table 2: Summary Statistics (Child) Year 1 \& Year 2

\begin{tabular}{lcc}
\hline & $\begin{array}{c}\text { Year 1 } \\
\text { Mean } \\
(\mathrm{sd})\end{array}$ & $\begin{array}{c}\text { Year } 2 \\
\text { Mean } \\
(\mathrm{sd})\end{array}$ \\
\hline \multirow{2}{*}{ Aggregate BSID-III } & 41.38 & 118.12 \\
Cognitive BSID-III & $(5.01)$ & $(15.20)$ \\
& 16.97 & 62.51 \\
Receptive communication BSID-III & $12.03)$ & $(5.84)$ \\
& 11.78 & 26.08 \\
Expressive communication BSID-III & $12.051)$ & $(5.490)$ \\
Birthweight/Weight & $(2.055)$ & $(5.639)$ \\
Head circumference & 3.279 & 13.00 \\
& $(0.537)$ & $(1.715)$ \\
Length/Heigth & 33.95 & 48.97 \\
& $(1.892)$ & $(1.779)$ \\
Developmental concerns & 50.23 & 87.74 \\
Hospitalizations & $(3.105)$ & $(3.779)$ \\
& 0.0684 & 0.107 \\
Observations & $(0.253)$ & $(0.309)$ \\
\hline & 0.117 & 0.253 \\
& $(0.322)$ & $(0.435)$ \\
\hline & & \\
& 1503 & 1103 \\
\hline & & \\
& & \\
& &
\end{tabular}

Notes: Hospitalizations: has your baby been hospitalized or seen at the ER? Developmental concerns: do you have concerns about your baby's health or development? 


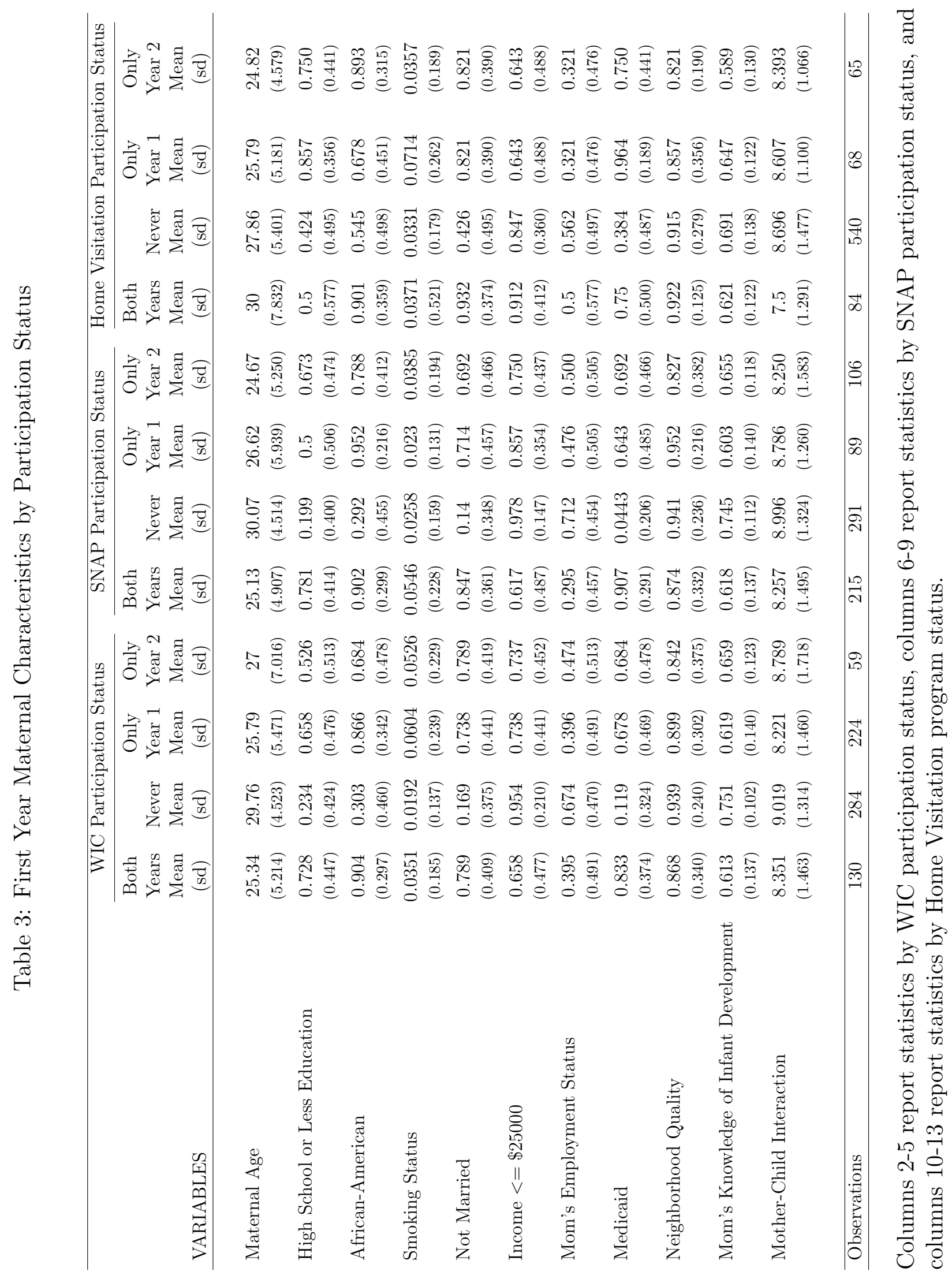




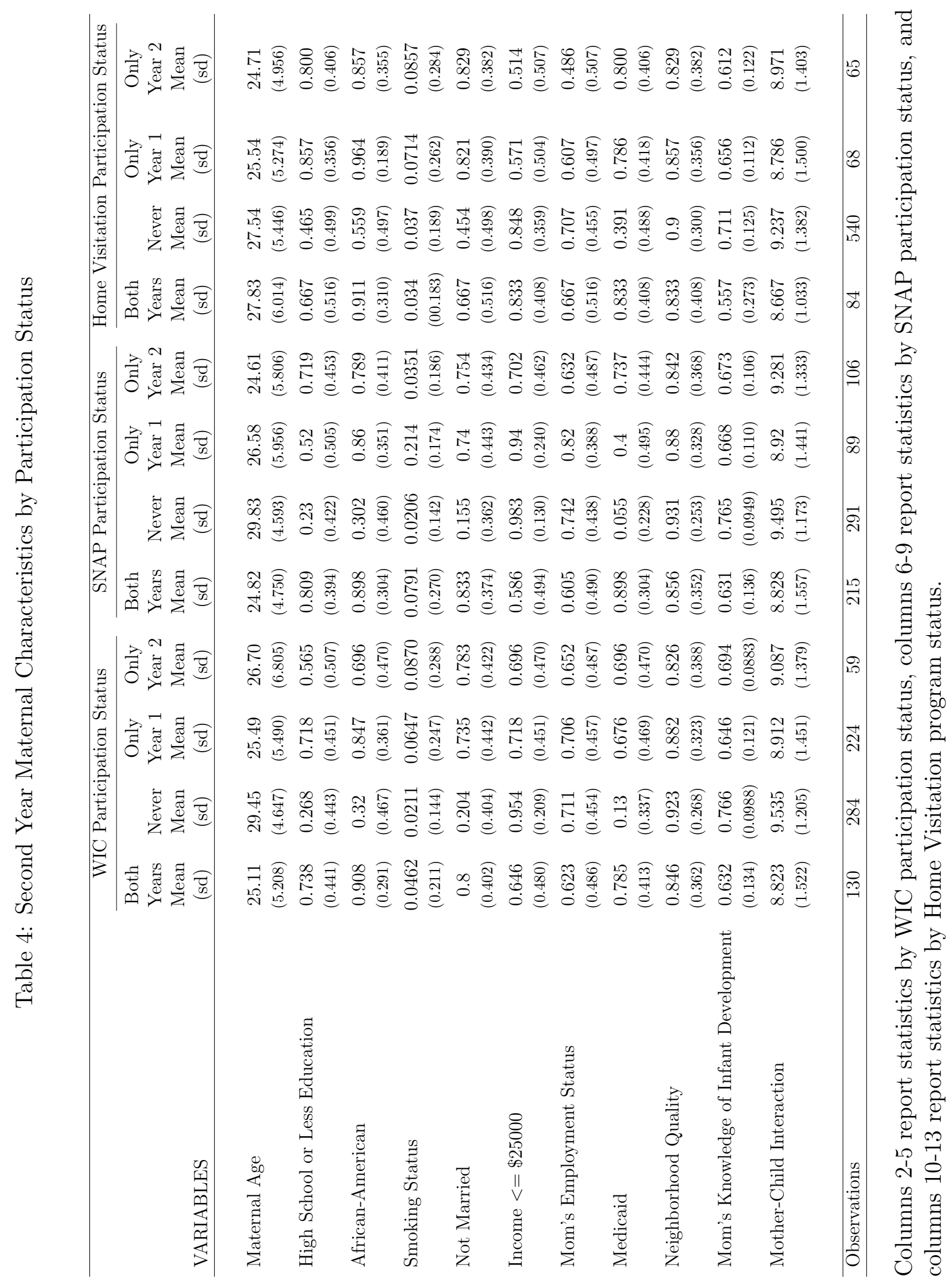


Table 5: Selection Equation - Year 1 Covariates

\begin{tabular}{|c|c|c|c|}
\hline VARIABLES & $\begin{array}{c}(1) \\
\text { WIC } \\
\text { Switchers }\end{array}$ & $\begin{array}{c}(2) \\
\text { SNAP } \\
\text { Switchers }\end{array}$ & $\begin{array}{c}(3) \\
\text { Home Visit } \\
\text { Switchers }\end{array}$ \\
\hline Maternal Age & $\begin{array}{r}-0.00426 \\
(0.00563)\end{array}$ & $\begin{array}{c}0.0225^{*} \\
(0.0116)\end{array}$ & $\begin{array}{c}-0.00440 \\
(0.0152)\end{array}$ \\
\hline Marital Status & $\begin{array}{c}-0.00257 \\
(0.0165)\end{array}$ & $\begin{array}{l}0.0154 \\
(0.0348)\end{array}$ & $\begin{array}{l}-0.0322 \\
(0.0584)\end{array}$ \\
\hline Maternal Education & $\begin{array}{c}0.00824 \\
(0.0287)\end{array}$ & $\begin{array}{l}0.116^{*} \\
(0.0595)\end{array}$ & $\begin{array}{l}0.0502 \\
(0.107)\end{array}$ \\
\hline Income & $\begin{array}{c}0.00921 \\
(0.0106)\end{array}$ & $\begin{array}{c}-0.0548^{* *} \\
(0.0259)\end{array}$ & $\begin{array}{r}-0.0159 \\
(0.0410)\end{array}$ \\
\hline Race & $\begin{array}{c}0.126 \\
(0.0906)\end{array}$ & $\begin{array}{l}0.310 \\
(0.197)\end{array}$ & $\begin{array}{l}0.441 \\
(0.315)\end{array}$ \\
\hline Smoking Status & $\begin{array}{l}0.0758 \\
(0.115)\end{array}$ & $\begin{array}{l}0.108 \\
(0.230)\end{array}$ & $\begin{array}{l}-0.155 \\
(0.318)\end{array}$ \\
\hline Wechsler intelligence scores & $\begin{array}{r}-0.000577 \\
(0.000906)\end{array}$ & $\begin{array}{l}0.00149 \\
(0.00188)\end{array}$ & $\begin{array}{c}-0.00173 \\
(0.00429)\end{array}$ \\
\hline Knowledge of infant development & $\begin{array}{c}-0.0396 \\
(0.200)\end{array}$ & $\begin{array}{c}0.099 \\
(0.393)\end{array}$ & $\begin{array}{c}0.721 \\
(0.761)\end{array}$ \\
\hline Neighborhood Quality & $\begin{array}{r}-0.0357 \\
(0.0952)\end{array}$ & $\begin{array}{l}0.211 \\
(0.147)\end{array}$ & $\begin{array}{l}0.0312 \\
(0.224)\end{array}$ \\
\hline Health insurance status & $\begin{array}{c}-0.00701 \\
(0.0295)\end{array}$ & $\begin{array}{c}-0.0590 \\
(0.0647)\end{array}$ & $\begin{array}{c}-0.241^{*} \\
(0.131)\end{array}$ \\
\hline Parent-Child Interaction & $\begin{array}{c}-0.0230 \\
(0.0192)\end{array}$ & $\begin{array}{c}0.0618^{*} \\
(0.0333)\end{array}$ & $\begin{array}{r}-0.0128 \\
(0.0715)\end{array}$ \\
\hline $\begin{array}{l}\text { Observations } \\
R^{2}\end{array}$ & $\begin{array}{c}287 \\
0.135\end{array}$ & $\begin{array}{c}191 \\
0.369\end{array}$ & $\begin{array}{c}153 \\
0.463\end{array}$ \\
\hline
\end{tabular}

Notes: Each dependent variable is 1 if the subject participated in the indicated nutrition support program in the first time period, and 0 otherwise. Robust standard errors in parentheses. ${ }^{*}, * *, * * *$ Significant at the $.10, .05$ and .01 level. 
Table 6: Selection Equation - Year 2 Covariates

\begin{tabular}{|c|c|c|c|}
\hline VARIABLES & $\begin{array}{c}(1) \\
\text { WIC } \\
\text { Switchers }\end{array}$ & $\begin{array}{c}(2) \\
\text { SNAP } \\
\text { Switchers }\end{array}$ & $\begin{array}{c}\text { (3) } \\
\text { Home Visit } \\
\text { Switchers }\end{array}$ \\
\hline Maternal Age & $\begin{array}{l}-0.00215 \\
(0.00466)\end{array}$ & $\begin{array}{c}0.0211^{*} \\
(0.0121)\end{array}$ & $\begin{array}{c}-0.00635 \\
(0.0220)\end{array}$ \\
\hline Marital Status & $\begin{array}{c}-0.0174 \\
(0.0156)\end{array}$ & $\begin{array}{c}-0.00267 \\
(0.0389)\end{array}$ & $\begin{array}{c}-0.0212 \\
(0.0604)\end{array}$ \\
\hline Maternal Education & $\begin{array}{c}-0.00443 \\
(0.0266)\end{array}$ & $\begin{array}{l}0.0849 \\
(0.0660)\end{array}$ & $\begin{array}{l}0.0143 \\
(0.0964)\end{array}$ \\
\hline Income & $\begin{array}{c}-0.000653 \\
(0.0105)\end{array}$ & $\begin{array}{c}-0.0606^{* *} \\
(0.0273)\end{array}$ & $\begin{array}{c}0.00906 \\
(0.0452)\end{array}$ \\
\hline Race & $\begin{array}{c}0.150 \\
(0.0974)\end{array}$ & $\begin{array}{l}0.340 \\
(0.190)\end{array}$ & $\begin{array}{l}0.460 \\
(0.253)\end{array}$ \\
\hline Smoking Status & $\begin{array}{l}0.0839 \\
(0.102)\end{array}$ & $\begin{array}{l}0.175 \\
(0.205)\end{array}$ & $\begin{array}{l}-0.397 \\
(0.335)\end{array}$ \\
\hline Welchesler intelligence scores & $\begin{array}{r}-0.000520 \\
(0.000834)\end{array}$ & $\begin{array}{l}0.00129 \\
(0.00226)\end{array}$ & $\begin{array}{c}0.000253 \\
(0.00479)\end{array}$ \\
\hline Knowledge of Infant Development & $\begin{array}{l}-0.167 \\
(0.175)\end{array}$ & $\begin{array}{l}-0.256 \\
(0.656)\end{array}$ & $\begin{array}{c}0.883 \\
(0.942)\end{array}$ \\
\hline Neighborhood quality & $\begin{array}{c}-0.00664 \\
(0.0886)\end{array}$ & $\begin{array}{l}0.0287 \\
(0.162)\end{array}$ & $\begin{array}{l}0.222 \\
(0.284)\end{array}$ \\
\hline Health Insurance Status & $\begin{array}{c}-0.0382 \\
(0.0340)\end{array}$ & $\begin{array}{c}0.00934 \\
(0.0731)\end{array}$ & $\begin{array}{c}0.0216 \\
(0.146)\end{array}$ \\
\hline Parent-Child Interaction & $\begin{array}{r}-0.0100 \\
(0.0161)\end{array}$ & $\begin{array}{r}-0.0676 \\
(0.0457)\end{array}$ & $\begin{array}{l}0.0146 \\
(0.0687)\end{array}$ \\
\hline $\begin{array}{l}\text { Observations } \\
R^{2}\end{array}$ & $\begin{array}{c}283 \\
0.175\end{array}$ & $\begin{array}{c}195 \\
0.196\end{array}$ & $\begin{array}{c}157 \\
0.230\end{array}$ \\
\hline
\end{tabular}

Notes: Each dependent variable is 1 if the subject participated in the indicated nutrition support program in the second time period, and 0 otherwise. Robust standard errors in parentheses. *, **, *** Significant at the .10, .05 and .01 level. 
Table 7: Nutrition Programs on Outcomes by Year

\begin{tabular}{|c|c|c|c|c|c|c|}
\hline VARIABLES & $\begin{array}{c}(1) \\
\text { Year } 1\end{array}$ & $\begin{array}{c}(2) \\
\text { Year } 1\end{array}$ & $\begin{array}{c}(3) \\
\text { Year } 1\end{array}$ & $\begin{array}{c}(4) \\
\text { Year } 2\end{array}$ & $\begin{array}{c}(5) \\
\text { Year } 2\end{array}$ & $\begin{array}{c}(6) \\
\text { Year } 2\end{array}$ \\
\hline \multicolumn{7}{|c|}{ Panel A: Aggregate Development } \\
\hline WIC & $\begin{array}{l}-0.111 \\
(0.214)\end{array}$ & $\begin{array}{l}-0.089 \\
(0.107)\end{array}$ & $\begin{array}{l}-0.113 \\
(0.112)\end{array}$ & $\begin{array}{c}-0.493^{* * *} \\
(0.06)\end{array}$ & $\begin{array}{c}-0.185^{* * *} \\
(0.077)\end{array}$ & $\begin{array}{c}-0.112 \\
(0.09)\end{array}$ \\
\hline SNAP & $\begin{array}{r}-0.17^{* *} \\
(0.090)\end{array}$ & $\begin{array}{c}-0.162^{*} \\
(0.12)\end{array}$ & $\begin{array}{l}-0.118 \\
(0.124)\end{array}$ & $\begin{array}{l}-0.009 \\
(0.007)\end{array}$ & $\begin{array}{l}-0.001 \\
(0.006)\end{array}$ & $\begin{array}{l}0.001 \\
(0.008)\end{array}$ \\
\hline Home Visitation & $\begin{array}{l}0.002 \\
(0.009)\end{array}$ & $\begin{array}{l}0.002 \\
(0.01)\end{array}$ & $\begin{array}{l}0.004 \\
(0.009)\end{array}$ & $\begin{array}{l}-0.016 \\
(0.009)\end{array}$ & $\begin{array}{l}-0.012 \\
(0.009)\end{array}$ & $\begin{array}{l}-0.003 \\
(0.008)\end{array}$ \\
\hline $\begin{array}{l}\text { Observations } \\
R^{2}\end{array}$ & $\begin{array}{l}895 \\
0.06\end{array}$ & $\begin{array}{l}864 \\
0.06\end{array}$ & $\begin{array}{l}807 \\
0.05\end{array}$ & $\begin{array}{c}993 \\
0.04\end{array}$ & $\begin{array}{l}866 \\
0.22\end{array}$ & $\begin{array}{l}766 \\
0.29\end{array}$ \\
\hline \multicolumn{7}{|l|}{ Panel B: Cognitive Skills } \\
\hline WIC & $\begin{array}{c}-0.175^{*} \\
(0.09)\end{array}$ & $\begin{array}{l}-0.06 \\
(0.109)\end{array}$ & $\begin{array}{l}-0.08 \\
(0.116)\end{array}$ & $\begin{array}{c}-0.48^{* * *} \\
(0.120)\end{array}$ & $\begin{array}{c}-0.15 * \\
(0.07)\end{array}$ & $\begin{array}{l}-0.08 \\
(0.07)\end{array}$ \\
\hline SNAP & $\begin{array}{l}-0.12 \\
(0.09)\end{array}$ & $\begin{array}{l}-0.02^{*} \\
(0.122)\end{array}$ & $\begin{array}{l}-0.02 \\
(0.128)\end{array}$ & $\begin{array}{l}-0.006 \\
(0.007)\end{array}$ & $\begin{array}{l}-0.003 \\
(0.007)\end{array}$ & $\begin{array}{l}0.001 \\
(0.006)\end{array}$ \\
\hline Home Visitation & $\begin{array}{l}0.005 \\
(0.009)\end{array}$ & $\begin{array}{l}0.006 \\
(0.01)\end{array}$ & $\begin{array}{l}0.008 \\
(0.01)\end{array}$ & $\begin{array}{l}-0.004 \\
(0.161)\end{array}$ & $\begin{array}{c}-0.001^{*} \\
(0.009)\end{array}$ & $\begin{array}{l}-0.004 \\
(0.009)\end{array}$ \\
\hline $\begin{array}{l}\text { Observations } \\
R^{2}\end{array}$ & $\begin{array}{l}895 \\
0.01\end{array}$ & $\begin{array}{l}853 \\
0.01\end{array}$ & $\begin{array}{l}807 \\
0.04\end{array}$ & $\begin{array}{c}993 \\
0.04\end{array}$ & $\begin{array}{l}866 \\
0.20\end{array}$ & $\begin{array}{l}766 \\
0.26\end{array}$ \\
\hline \multicolumn{7}{|c|}{ Panel C: Receptive Communication } \\
\hline WIC & $\begin{array}{l}0.024 \\
(0.09)\end{array}$ & $\begin{array}{l}0.029 \\
(0.107)\end{array}$ & $\begin{array}{l}-0.005 \\
(0.116)\end{array}$ & $\begin{array}{c}-0.49^{* * *} \\
(0.120)\end{array}$ & $\begin{array}{l}-0.13^{*} \\
(0.077)\end{array}$ & $\begin{array}{c}-0.012 \\
(0.09)\end{array}$ \\
\hline SNAP & $\begin{array}{c}-0.19^{* *} \\
(0.091)\end{array}$ & $\begin{array}{l}-0.2^{*} \\
(0.114)\end{array}$ & $\begin{array}{l}-0.17 \\
(0.006)\end{array}$ & $\begin{array}{c}-0.013^{*} \\
(0.007)\end{array}$ & $\begin{array}{l}-0.04 \\
(0.006)\end{array}$ & $\begin{array}{l}0.008 \\
(0.001)\end{array}$ \\
\hline Home Visitation & $\begin{array}{l}0.002 \\
(0.009)\end{array}$ & $\begin{array}{l}0.001 \\
(0.01)\end{array}$ & $\begin{array}{l}0.0684 \\
(0.009)\end{array}$ & $\begin{array}{l}-0.016 \\
(0.161)\end{array}$ & $\begin{array}{c}-0.016^{*} \\
(0.009)\end{array}$ & $\begin{array}{l}-0.007 \\
(0.008)\end{array}$ \\
\hline $\begin{array}{l}\text { Observations } \\
R^{2}\end{array}$ & $\begin{array}{c}895 \\
0.003\end{array}$ & $\begin{array}{c}864 \\
0.029\end{array}$ & $\begin{array}{c}807 \\
0.039\end{array}$ & $\begin{array}{c}993 \\
0.04\end{array}$ & $\begin{array}{l}866 \\
0.20\end{array}$ & $\begin{array}{l}766 \\
0.26\end{array}$ \\
\hline \multicolumn{7}{|c|}{ Panel D: Expressive Communication } \\
\hline WIC & $\begin{array}{l}-0.12 \\
(0.09)\end{array}$ & $\begin{array}{l}-0.15 \\
(0.109)\end{array}$ & $\begin{array}{l}-0.19^{*} \\
(0.113)\end{array}$ & $\begin{array}{c}-0.38^{* * *} \\
(0.06)\end{array}$ & $\begin{array}{c}-0.15^{*} \\
(0.07)\end{array}$ & $\begin{array}{c}-0.13^{*} \\
(0.08)\end{array}$ \\
\hline SNAP & $\begin{array}{l}-0.1 \\
(0.09)\end{array}$ & $\begin{array}{l}-0.15 \\
(0.121)\end{array}$ & $\begin{array}{l}-0.13 \\
(0.125)\end{array}$ & $\begin{array}{l}-0.005 \\
(0.007)\end{array}$ & $\begin{array}{l}-0.003 \\
(0.007)\end{array}$ & $\begin{array}{l}0.003 \\
(0.006)\end{array}$ \\
\hline Home Visitation & $\begin{array}{l}-0.002 \\
(0.009)\end{array}$ & $\begin{array}{c}-0.001 \\
(0.01)\end{array}$ & $\begin{array}{l}-0.001 \\
(0.009)\end{array}$ & $\begin{array}{l}-0.01 \\
(0.009)\end{array}$ & $\begin{array}{c}-0.001^{*} \\
(0.009)\end{array}$ & $\begin{array}{l}-0.009 \\
(0.008)\end{array}$ \\
\hline $\begin{array}{l}\text { Observations } \\
R^{2}\end{array}$ & $\begin{array}{c}895 \\
0.007\end{array}$ & $\begin{array}{l}853 \\
0.03\end{array}$ & $\begin{array}{l}807 \\
0.05\end{array}$ & $\begin{array}{l}993 \\
0.3\end{array}$ & $\begin{array}{l}866 \\
0.12\end{array}$ & $\begin{array}{l}766 \\
0.22\end{array}$ \\
\hline $\begin{array}{l}\text { Demographic \& Medicaid } \\
\text { Psychological Controls }\end{array}$ & & $\mathrm{Y}$ & $\begin{array}{l}\mathrm{Y} \\
\mathrm{Y}\end{array}$ & & $\mathrm{Y}$ & $\begin{array}{l}\mathrm{Y} \\
\mathrm{Y}\end{array}$ \\
\hline
\end{tabular}

Notes: Dependent variable is the level of aggregate development, receptive communication, cognitive scores, and expressive communication z-scores in years 1 and 2. Demographic and Medicaid controls include gender, Medicaid, race, income, education level, marital status, maternal age at birth. Psychological Controls include knowledge of infant development, parent-child interaction total score, maternal Wechsler abbreviated scale of intelligence III total scores, child potential inventory loneliness total score, child abuse potential inventory unhappiness score total score, behavioral problems total score, child dysfunctional interaction score total score, developmental concerns, neighborhood quality, sickness not requiring visit to doctor, evaluation by a health provider, maternal smoking, and measure of emotional stability total score. Robust standard errors in parentheses. *, **, *** Significant at the .10, .05 and .01 level. 
Table 8: Nutrition Programs on Change in Outcomes

\begin{tabular}{|c|c|c|c|c|c|c|}
\hline VARIABLES & $(1)$ & $(2)$ & $(3)$ & (4) & $(5)$ & $(6)$ \\
\hline \multicolumn{7}{|c|}{ Panel A: Aggregate Development } \\
\hline WIC & $\begin{array}{c}0.158^{* *} \\
(0.08)\end{array}$ & & & $\begin{array}{c}0.162^{* *} \\
(0.08)\end{array}$ & $\begin{array}{l}0.10 \\
(0.09)\end{array}$ & $\begin{array}{l}0.168^{*} \\
(0.104)\end{array}$ \\
\hline SNAP & & $\begin{array}{c}0.01 * * * \\
(0.001)\end{array}$ & & $\begin{array}{c}0.01^{* * *} \\
(0.001)\end{array}$ & $\begin{array}{c}0.01^{* * *} \\
(0.002)\end{array}$ & $\begin{array}{c}0.01^{* * *} \\
(0.002)\end{array}$ \\
\hline Home Visitation & & & $\begin{array}{c}0.005^{* * *} \\
(0.001)\end{array}$ & $\begin{array}{c}0.006^{* * *} \\
(0.001)\end{array}$ & $\begin{array}{c}0.008^{* * *} \\
(0.001)\end{array}$ & $\begin{array}{c}0.14 \\
(0.10)\end{array}$ \\
\hline Observations & 1,694 & 1703 & 1,697 & 1688 & 1583 & 1525 \\
\hline$R^{2}$ & 0.03 & 0.02 & 0.02 & 0.04 & 0.06 & 0.06 \\
\hline \multicolumn{7}{|l|}{ Panel B: Cognitive Skills } \\
\hline WIC & $\begin{array}{l}0.063 \\
(0.09)\end{array}$ & & & $\begin{array}{l}0.065 \\
(0.09)\end{array}$ & $\begin{array}{l}0.022 \\
(0.10)\end{array}$ & $\begin{array}{l}0.022 \\
(0.120)\end{array}$ \\
\hline SNAP & & $\begin{array}{c}0.007^{* * *} \\
(0.001)\end{array}$ & & $\begin{array}{c}0.007^{* * *} \\
(0.001)\end{array}$ & $\begin{array}{c}0.007^{* * *} \\
(0.002)\end{array}$ & $\begin{array}{c}0.007^{* * *} \\
(0.002)\end{array}$ \\
\hline Home Visitation & & & $\begin{array}{c}0.02^{* * *} \\
(0.001)\end{array}$ & $\begin{array}{c}0.017^{* * *} \\
(0.001)\end{array}$ & $\begin{array}{c}0.017^{* * *} \\
(0.001)\end{array}$ & $\begin{array}{l}0.103 \\
(0.18)\end{array}$ \\
\hline Observations & 1,694 & 1703 & 1,697 & 1688 & 1583 & 1525 \\
\hline$R^{2}$ & 0.02 & 0.02 & 0.02 & 0.04 & 0.08 & 0.08 \\
\hline \multicolumn{7}{|c|}{ Panel C: Receptive Communication } \\
\hline WIC & $\begin{array}{c}0.255^{* * *} \\
(0.08)\end{array}$ & & & $\begin{array}{c}0.266^{* * *} \\
(0.120)\end{array}$ & $\begin{array}{c}0.209^{* * *} \\
(0.120)\end{array}$ & $\begin{array}{c}0.346^{* * *} \\
(0.120)\end{array}$ \\
\hline SNAP & & $\begin{array}{c}0.0136^{* * *} \\
(0.001)\end{array}$ & & $\begin{array}{c}0.013^{* * *} \\
(0.002)\end{array}$ & $\begin{array}{c}0.013^{* * *} \\
(0.002)\end{array}$ & $\begin{array}{c}0.012^{* * *} \\
(0.002)\end{array}$ \\
\hline Home Visitation & & & $\begin{array}{c}0.0038^{* * *} \\
(0.002)\end{array}$ & $\begin{array}{c}0.004^{* * *} \\
(0.001)\end{array}$ & $\begin{array}{c}0.007 \\
(0.001)\end{array}$ & $\begin{array}{c}0.37 \\
(0.157)\end{array}$ \\
\hline Observations & 1,694 & 1703 & 1,697 & 1688 & 1583 & 1525 \\
\hline$R^{2}$ & 0.117 & 0.115 & 0.107 & 0.114 & 0.114 & 0.114 \\
\hline \multicolumn{7}{|c|}{ Panel D: Expressive Communication } \\
\hline WIC & $\begin{array}{c}0.11 \\
(0.08)\end{array}$ & & & $\begin{array}{c}0.11 \\
(0.08)\end{array}$ & $\begin{array}{c}0.05 \\
(0.09)\end{array}$ & $\begin{array}{l}0.127 \\
(0.104)\end{array}$ \\
\hline SNAP & & $\begin{array}{c}0.001^{* * *} \\
(0.001)\end{array}$ & & $\begin{array}{c}0.001^{* * *} \\
(0.001)\end{array}$ & $\begin{array}{c}0.001^{* * *} \\
(0.002)\end{array}$ & $\begin{array}{c}0.001^{* * *} \\
(0.002)\end{array}$ \\
\hline Home Visitation & & & $\begin{array}{c}0.005^{* * *} \\
(0.001)\end{array}$ & $\begin{array}{c}0.005^{* * *} \\
(0.001)\end{array}$ & $\begin{array}{c}0.005^{* * *} \\
(0.001)\end{array}$ & $\begin{array}{l}0.104 \\
(0.17)\end{array}$ \\
\hline Observations & 1,694 & 1703 & 1,697 & 1688 & 1583 & 1525 \\
\hline$R^{2}$ & 0.02 & 0.02 & 0.02 & 0.04 & 0.08 & 0.08 \\
\hline $\begin{array}{l}\text { Demographic \& Medicaid } \\
\text { Psychological Controls }\end{array}$ & & & & & Y & $\begin{array}{l}\mathrm{Y} \\
\mathrm{Y}\end{array}$ \\
\hline
\end{tabular}

Notes: Dependent variable is the change in aggregate development, receptive communication, cognitive scores, and expressive communication z-scores from year 1 to year 2. Demographic and Medicaid controls include change in Medicaid status, income, marital status and employment. Psychological Controls include change in maternal knowledge of infant development, parent-child interaction total score, child potential inventory loneliness total score, child abuse potential inventory unhappiness score total score, behavioral problems total score, child dysfunctional interaction score total score, developmental concerns, neighborhood quality, sickness not requiring visit to doctor, evaluation by a health provider, and measure of emotional stability total score. Robust standard errors in parentheses. *, **, *** Significant at the .10, .05 and .01 level. 
Table 9: Marginal Effect of WIC Participation on Skills Formation with Additional TimeVarying Controls

\begin{tabular}{lcccc}
\hline & $\begin{array}{c}(1) \\
\text { Aggregate } \\
\text { VARIABLES }\end{array}$ & $\begin{array}{c}(2) \\
\text { Cognitive } \\
\text { Scores }\end{array}$ & $\begin{array}{c}(3) \\
\text { Receptive } \\
\text { Communication }\end{array}$ & $\begin{array}{c}(4) \\
\text { Expressive } \\
\text { Communication }\end{array}$ \\
\hline Parent-Child Interaction & $0.20^{* *}$ & 0.0561 & $0.3490^{* * *}$ & $0.1667^{*}$ \\
Illness w/o MD & $(0.101)$ & $(0.111)$ & $(0.107)$ & $(0.097)$ \\
Evaluated & $0.20^{* *}$ & 0.0653 & $0.3261^{* * *}$ & $0.1672^{*}$ \\
& $(0.112)$ & $(0.112)$ & $(0.107)$ & $(0.099)$ \\
Emotional Stability & $0.19^{*}$ & 0.0653 & $0.3224^{* * *}$ & $0.1612^{*}$ \\
Loneliness & $(0.112)$ & $(0.112)$ & $(0.107)$ & $(0.097)$ \\
Behavioral Problems & $0.19^{*}$ & 0.07156 & $0.3201^{* * *}$ & $0.1608^{*}$ \\
& $(0.103)$ & $(0.114)$ & $(0.107)$ & $(0.097)$ \\
Happiness & $0.19^{*}$ & 0.070 & $0.3189^{* * *}$ & $0.1605^{*}$ \\
& $(0.102)$ & $(0.114)$ & $(0.107)$ & $(0.097)$ \\
& $0.19^{*}$ & 0.079 & $0.3221^{* * *}$ & $0.1609^{*}$ \\
& $(0.102)$ & $(0.114)$ & $(0.108)$ & $(0.097)$ \\
Observations & $0.19^{*}$ & 0.0743 & $0.3217^{* * *}$ & $0.1610^{*}$ \\
\hline
\end{tabular}

Notes: Each cell is the estimated effect of WIC participation on the dependent variable as indicated in the column title with the cumulative addition of the indicated explanatory variables in addition to the full statistical controls of Table 5, Specification 6. Parent-Child Interaction: Nursing Child Assessment Parent-Child Interaction Teaching Scale. Illness w/o MD: Child had an illness not requiring a visit to a medical doctor. Evaluated: Baby is evaluated by any health provider for any reason. Emotional Stability: 40 item measurement of personal and interpersonal emotional stability. Loneliness: Child Abuse Potential Inventory Loneliness Total Score. Behavioral Problems: Behavioral Problems Total Score. Happiness: Child Abuse Potential Inventory Happiness Total Score.

Year dummies are included in all models.

Clustered by study id standard errors in parentheses.

* Significant at the 10 level.

** Significant at the .05 level.

*** Significant at the .01 level. 
Table 10: Foods rich in animal protein and critical nutrients distribution across WIC status

\begin{tabular}{|c|c|c|c|c|}
\hline & $\begin{array}{l}\text { WIC Group } \\
\text { Mean (SD) }\end{array}$ & $\begin{array}{l}\text { Non-WIC } \\
\text { Mean (SD) }\end{array}$ & $\begin{array}{c}\text { Median Test } \\
\text { P-value }\end{array}$ & $\begin{array}{c}\text { Mann-Whitney } \\
\text { P-value }\end{array}$ \\
\hline \multicolumn{5}{|l|}{ VARIABLES } \\
\hline Lunch meats (ounces) & $\begin{array}{c}1.27 \\
(1.212)\end{array}$ & $\begin{array}{c}0.70 \\
(0.645)\end{array}$ & 0.001 & 0.001 \\
\hline Beef or pork (ounces) & $\begin{array}{c}2.40 \\
(2.146)\end{array}$ & $\begin{array}{c}1.51 \\
(1.091)\end{array}$ & 0.001 & 0.001 \\
\hline Meat, fish, poultry (ounces) & $\begin{array}{c}5.81 \\
(3.974)\end{array}$ & $\begin{array}{c}3.88 \\
(2.155)\end{array}$ & 0.001 & 0.001 \\
\hline Eggs, lean meat (ounces) & $\begin{array}{c}0.68 \\
(0.643)\end{array}$ & $\begin{array}{c}0.41 \\
(0.418)\end{array}$ & 0.001 & 0.001 \\
\hline Seafood, high in Omega-3 (ounces) & $\begin{array}{l}0.137 \\
(0.182)\end{array}$ & $\begin{array}{l}0.151 \\
(0.197)\end{array}$ & 0.001 & 0.001 \\
\hline Seafood, low in Omega-3 (ounces) & $\begin{array}{c}0.54 \\
(0.634)\end{array}$ & $\begin{array}{c}0.39 \\
(0.444)\end{array}$ & 0.001 & 0.001 \\
\hline Folic Acid, (mcg) & $\begin{array}{c}239.76 \\
(159.183)\end{array}$ & $\begin{array}{l}180.75 \\
(103.79)\end{array}$ & 0.001 & 0.001 \\
\hline Iron, (mg) & $\begin{array}{c}20.31 \\
(10.922)\end{array}$ & $\begin{array}{l}15.85 \\
(6.435)\end{array}$ & 0.001 & 0.001 \\
\hline Vitamin B-12, (mcg) & $\begin{array}{c}6.83 \\
(3.955)\end{array}$ & $\begin{array}{c}5.14 \\
(2.837)\end{array}$ & 0.001 & 0.001 \\
\hline Vitamin B-6, (mcg) & $\begin{array}{c}2.66 \\
(1.41)\end{array}$ & $\begin{array}{c}2.14 \\
(0.877)\end{array}$ & 0.001 & 0.001 \\
\hline Observations & 1,068 & 1,068 & 1,068 & 1,068 \\
\hline
\end{tabular}

Notes: Mann-Whitney (Ranksum) test the hypothesis that two independent samples are from populations with the same distribution. Median test nonparametric equality of medians. K-S Test is the Kolmogorov-Smirnov equality of distributions test. 


\section{A CANDLE}

The CANDLE study was funded by the Urban Child Institute (UCI) with the following specific research aims:

- Determine whether nutrition factors (prenatal and infant diet) improve cognitive function during the first years of life.

- Estimate the effect that in utero exposure to environmental toxins can have on birth outcomes and neurocognitive development in a child's first three years of life.

- Explore psychosocial phenomena and patterns of mothers and children and assess the effects that intra- and interpersonal factors and social development can have on cognitive development in children over time.

- Identify the genetic variants that contribute to mothers' and children's responses to nutrient intake and the physical and psychosocial environment that consequently contributes to birth weight and neurocognitive development.

Roughly 1,500 pregnant women were enrolled throughout the duration of the study. There were eight in-person data-collection points per family (two prenatal clinic visits, one hospital visit at delivery, three clinic visits, and two home visits) and nine phone-based assessments that occurred every 3 months, starting when the child in the study was 3 months old. Data collection began during the second trimester and continued until the child's third birthday. CANDLE recruited 1,503 healthy pregnant women between 16.0 and 28.0 weeks of gestation, who had normal singleton fetal pregnancies and lived in Shelby County, TN. (Sontag-Padilla et al. 2016)

The design of and results from the UCI CANDLE study provide an opportunity for researchers to examine early drivers and markers of healthy early childhood development and the influences of genetics, biology, family and community environment within a large 
racially and economically diverse sample. The multiple data points and multiple types of data allow researchers to examine both objective (e.g., bio specimen) and self-reported (e.g., survey) measures.

The study population includes women, recruited during their second trimesters of pregnancy, and the children who were born at the birth visit. The UCI CANDLE study considered a woman eligible for participation if she met all the following criteria:

- A resident of Shelby County, TN

- Pregnant between 16 weeks and 28 weeks of gestation

- Between 16 and 40 years of age

- Can speak and understand English

- A low-risk ${ }^{5}$, singleton pregnancy

- Planned to deliver at one of the five participating health care settings in Shelby County, $\mathrm{TN}^{6}$

Demographically, the CANDLE cohort closely resembles the Shelby County, TN census tract, as shown in Table 1. The percentage of the population which is African-American and Caucasian closely match, as does educational attainment. The income of CANDLE participants appears somewhat lower than the Shelby County census tract, as might be expected given the younger age of CANDLE participants relative to the population.

\footnotetext{
${ }^{5}$ The UCI defined a pregnancy as low risk if it lacked all of the following: chronic hypertension requiring therapy or vascular disease requiring therapy; maternal red-cell alloimmunization except Rhesus (Rh) factor; hemoglobinopathy, including sickle-cell trait and severe iron-deficiency anemia (hemoglobin less than 9); insulin-dependent diabetes; appreciable renal or cardiopulmonary disease; prolapsed or ruptured membranes; oligohydramnios; complete placenta previa; endocrine disease; collagen disease (e.g., lupus erythematosus or scleroderma); active or chronic hepatitis; renal disease; pulmonary or heart disease requiring therapeutic medication or limitation of physical activity; major fetal anomaly (e.g., aneuploidy, major organ-system defect); and human immunodeficiency virus.

${ }^{6}$ Baptist Memorial Hospital-Memphis, Methodist Le Bonheur Germantown Hospital, Regional Medical Center, Saint Francis Hospital-Bartlett, and Saint Francis Hospital-Memphis.
} 


\section{The CANDLE Study: Measurement Collection Timeline}

\section{Conditions Affecting Neurocognitive Development and Learning in Early Childhood}

\section{Maternal Measurements}

\begin{tabular}{|l|c|c|c|c|c|c|c|c|c|}
\hline Prenatial \& Birth & M1 & M2 & M3 & HV1 & CV1 & CV2 & HV2 & CV3 & CV4 \\
\hline $\begin{array}{l}\text { Maternal Baseline Enrollment Data Form } \\
\text { Includes BIII measurements, substance abuse history, OB/GYN history, } \\
\text { medical historv, sexual historv }\end{array}$ & $\checkmark$ & & & & & & & & \\
\hline $\begin{array}{l}\text { Lad Updates and Complications Form } \\
\text { Includes complication historv, tvpe of labor, deliverv classification }\end{array}$ & & & $\checkmark$ & & & & & & \\
\hline Lad Summary Form & & & $\checkmark$ & & & & & & \\
\hline $\begin{array}{l}\text { Neonatal Summary Form } \\
\text { Includes birth status, infant gender, discharge diagnosis }\end{array}$ & & & $\checkmark$ & & & & & & \\
\hline
\end{tabular}

Demographics

\begin{tabular}{l|l|l|l|l|l|l|l|l|} 
M1 & M2 & M3 & HV1 & CV1 & $\mathrm{CV}_{2}$ & HV2 & $\mathrm{CV}_{3}$ & $\mathrm{CV}$ \\
\hline
\end{tabular}

Demographics Survey

Includes gender, language, age, race, ethnicity, income, education,

insurance status, marital status, paternal information

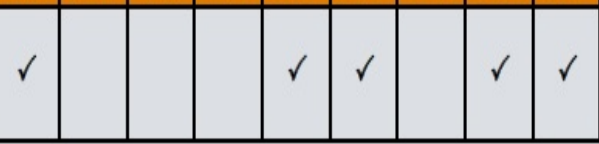

\begin{tabular}{|l|c|c|c|c|c|c|c|c|c|}
\hline Biological Samples & M1 & M2 & M3 & HV1 & CV1 & CV2 & HV2 & CV3 & CV 4 \\
\hline Blood & $\checkmark$ & $\checkmark$ & $\checkmark$ & & & & & & \\
\hline Urine & $\checkmark$ & $\checkmark$ & $\checkmark$ & & & & & & \\
\hline
\end{tabular}

\section{Nutrition}

\begin{tabular}{l|l|l|l|l|l|l|l|l} 
M1 & M2 & M3 & HV1 & CV1 & $\mathrm{CV}_{2}$ & HV2 & $\mathrm{CV}_{3}$ & $\mathrm{CV}$ \\
\hline
\end{tabular}

Food Frequency Questionnaire

Choline Inhibitor Questionnaire

Infant Feeding Practices Questionnaire (IFQ)

Food Program Questionnaire

24 Hour Food Recall

Comprehensive Feeding Practices Questionnaire

\section{Health}

M1 M2 M3 HV1 CV1 CV2 HV2 CV3 CV4

Family Health History

Includes family history of substance abuse, developmental/learning

disabilities, dementia, Autism, psychiatric disorders, cardiovascular health, obesity and related complications

CAGE Substance Abuse Screening Tool

Maternal Exam

Residence Establishment and Lead Risk Assessment

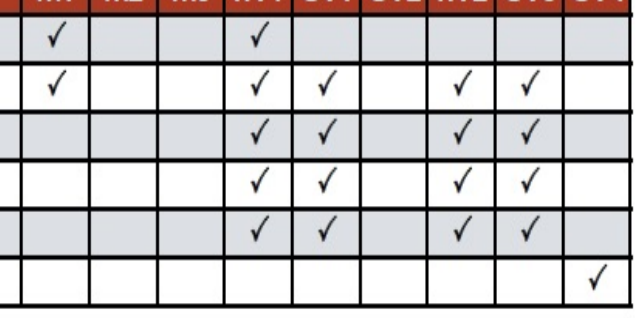

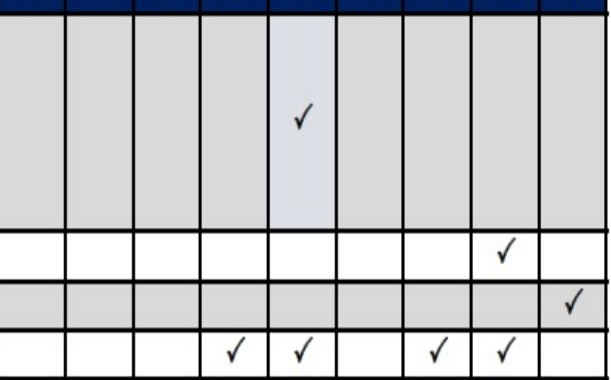




\begin{tabular}{|l|c|c|c|c|c|c|c|c|c|}
\hline Mental Heallh & M1 & M2 & M3 & HV1 & CV1 & CV2 & HV2 & CV3 & CV4 \\
\hline Temperament Evaluation (TEMPS) & $\checkmark$ & & & & & $\checkmark$ & & & \\
\hline Brief Symptom Inventory (BSI) & & $\checkmark$ & & & $\checkmark$ & $\checkmark$ & & $\checkmark$ & $\checkmark$ \\
\hline Rosenberg Self-Esteem Questionnaire & & $\checkmark$ & & & & $\checkmark$ & & & \\
\hline Edinburgh Post-Natal Depression Scale (EPDS) & & & & $\checkmark$ & $\checkmark$ & & & & \\
\hline NEO Personality Inventory & & & & & & & & $\checkmark$ & \\
\hline State Trait Anxiety Inventory (STAl) & & & & & & & & $\checkmark$ & \\
\hline Center for Epidemiological Studies Depression Scale (CESD) & & & & & & & & & $\checkmark$ \\
\hline
\end{tabular}

\begin{tabular}{|l|c|c|c|c|c|c|c|c|c|}
\hline Cognilive & M1 & M2 & M3 & HV1 & CV1 & CV2 & HV2 & CV3 & CV4 \\
\hline Wechsler Abbreviated Scale of Intelligence III: Subscales & & & & & $\checkmark$ & & & & \\
\hline Wechsler Individual Achievement Test III-Word Reading & & & & & & & & $\checkmark$ & \\
\hline
\end{tabular}

\begin{tabular}{|l|c|c|c|c|c|c|c|c|c|}
\hline Psychosocial & M1 & M2 & M3 & HV1 & CV1 & CV2 & HV2 & CV3 & CV4 \\
\hline Conflict Tactics Scale - 25 & & $\checkmark$ & & & & $\checkmark$ & & & $\checkmark$ \\
\hline Traumatic Life Events Questionnaire & & $\checkmark$ & & & & & & $\checkmark$ & \\
\hline Social Support Questionnaire - 6 & & $\checkmark$ & & & & $\checkmark$ & & & \\
\hline Knowledge of Infant Development Inventory (KIDI) & & $\checkmark$ & & & & $\checkmark$ & & & \\
\hline $\begin{array}{l}\text { Household Questionnaire } \\
\text { Includes who lives in the home, feelines about neighborhood }\end{array}$ & & & & $\checkmark$ & & & $\checkmark$ & $\checkmark$ & $\checkmark$ \\
\hline Child Abuse Potential Inventory (CAPI) & & & & & $\checkmark$ & $\checkmark$ & & $\checkmark$ & \\
\hline Parenting Stress Index (PSI) & & & & & $\checkmark$ & $\checkmark$ & & $\checkmark$ & $\checkmark$ \\
\hline $\begin{array}{l}\text { Child Care Arrangements Questionnaire (CCI) } \\
\text { Includes who cares for child, location, type of child care (e.g. organized day } \\
\text { care) }\end{array}$ & & & & & $\checkmark$ & $\checkmark$ & & $\checkmark$ & \\
\hline HOME Inventory & & & & & & & & \\
\hline Parental Incarceration & & & & & & & & & $\checkmark$ \\
\hline Parenting Relationship Questionnaire & & & & & & & & & $\checkmark$ \\
\hline
\end{tabular}

\section{Child Measurements}

\begin{tabular}{|l|c|c|c|c|c|c|c|c|c|}
\hline Prenatal \& Birth & M1 & M2 & M3 & HV1 & CV1 & CV2 & HV2 & CV3 & CV4 \\
\hline LED Complications Form & & & $\checkmark$ & & & & & & \\
\hline LqD Summary Form & & & $\checkmark$ & & & & & & \\
\hline Neonatal Summary Form & & & $\checkmark$ & & & & & & \\
\hline
\end{tabular}

\begin{tabular}{|l|c|c|c|c|c|c|c|c|c|}
\hline Biological Samples & M1 & M2 & M3 & HV1 & CV1 & CV2 & HV2 & CV3 & CV4 \\
\hline Umbilical Cord Blood & & & $\checkmark$ & & & & & & \\
\hline Placental Tissue & & & $\checkmark$ & & & & & & \\
\hline Blood & & & $\checkmark$ & & & & & & $\checkmark$ \\
\hline
\end{tabular}




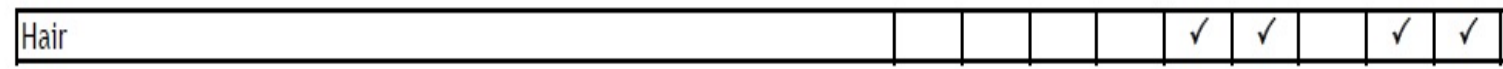

\begin{tabular}{|l|c|c|c|c|c|c|c|c|c|}
\hline Nutrition & M1 & M2 & M3 & HV1 & CV1 CV2 & HV2 & CV3 & CV4 \\
\hline Food Frequency Questionnaire & $\checkmark$ & & & $\checkmark$ & & & & & \\
\hline Choline Inhibitor Questionnaire & $\checkmark$ & & & $\checkmark$ & $\checkmark$ & & $\checkmark$ & $\checkmark$ & \\
\hline Infant Feeding Practices Questionnaire & & & & $\checkmark$ & $\checkmark$ & & $\checkmark$ & $\checkmark$ & \\
\hline Food Program Questionnaire & & & & $\checkmark$ & $\checkmark$ & & $\checkmark$ & $\checkmark$ & \\
\hline 24 Hour Food Recall & & & & $\checkmark$ & $\checkmark$ & & $\checkmark$ & $\checkmark$ & \\
\hline Comprehennive Feeding Practices Questionnaire & & & & & & & & & $\checkmark$ \\
\hline
\end{tabular}

\begin{tabular}{|c|c|c|c|c|c|c|c|c|c|}
\hline Heallh & M1 & M2 & M3 & IV1 & v1 & SV2 & IV2 & $\mathrm{CV}_{\mathrm{s}}$ & \\
\hline $\begin{array}{l}\text { Child Health Update Form } \\
\text { Includes hospitalizations, illnesses, weieht }\end{array}$ & & & & $\checkmark$ & $\checkmark$ & & $\checkmark$ & $\checkmark$ & \\
\hline Child Exam & & & & & $\checkmark$ & $\checkmark$ & & $\checkmark$ & $\checkmark$ \\
\hline $\begin{array}{l}\text { Brief Infant Sleee Questionnaire (BISQ) } \\
\text { Asked at CVI "Where does vour child sleep at nieht?" }\end{array}$ & & & & & $\checkmark$ & & $\checkmark$ & $\checkmark$ & \\
\hline Child Sleep Habits & & & & & & & & & $\checkmark$ \\
\hline Asthma and Environment Questionnaire & & & & & & & & & 1 \\
\hline Atopy History & & & & & & & & & $\checkmark$ \\
\hline \begin{tabular}{|l|} 
Children with Special Health Care Needs Screener \\
Includes medications; medical, behavioral, or health conditions; \\
educational services; PT, OT, speech therapy; anthropometry measurements
\end{tabular} & & & & & $\checkmark$ & $\checkmark$ & & $\checkmark$ & \\
\hline
\end{tabular}

\begin{tabular}{|l|c|c|c|c|c|c|c|c|c|}
\hline Cognilive & M1 & M2 & M3 & HV1 & CV1 & CV2 & HV2 & CV3 & CV4 \\
\hline BAYLEY Scales of Infant Development III & & & & & $\checkmark$ & $\checkmark$ & & $\checkmark$ & \\
\hline Bracken School Readiness Assessment - 3 & & & & & & & & $\checkmark$ & \\
\hline Stanford-Binet 5 & & & & & & & & & $\checkmark$ \\
\hline Behavior Rating Inventory of Executive Functioning - Preschool (BRIEF-P) & & & & & & & & & $\checkmark$ \\
\hline
\end{tabular}

\begin{tabular}{|l|c|c|c|c|c|c|c|c|c|}
\hline Socioemolional & M1 & M2 & M3 & HV1 & CV1 & CV2 & HV2 & CV3 & CV4 \\
\hline Brief Infant-Toddler Social and Emotional Assessment (BITSEA) & & & & & $\checkmark$ & $\checkmark$ & & & \\
\hline Scales of Independent Behavior - R & & & & & $\checkmark$ & $\checkmark$ & & $\checkmark$ & $\checkmark$ \\
\hline Modified Checklist of Autism in Toddlers (MCHAT) & & & & & & $\checkmark$ & & & \\
\hline Archenbach Test Observation Score & & & & & & & & $\checkmark$ & \\
\hline Child Autism Rating Scale (CARS) & & & & & & & & $\checkmark$ & \\
\hline Child Behavior Checklist (CBCL) & & & & & & & & & \\
\hline
\end{tabular}




\begin{tabular}{|l|l|l|l|l|l|l|l|l|l|}
\hline Child Opportunity Index & & & & & & & & & \\
\hline Geocoded and Census Data & & & & & & & & & \\
\hline TennCare Participation & & & & & & & & & \\
\hline Insurance Status (e.g. WIC, SNAP) & & & & $\checkmark$ & $\checkmark$ & & & & \\
\hline
\end{tabular}

\section{Phone Visit Measures}

\begin{tabular}{|l|c|c|c|c|c|c|c|c|c|}
\hline Measurement & PV1 & PV2 & PV3 & PV4 & PV5 & PV6 & PV7 & PV8 & PV9 \\
\hline Sleep Questionnaire & $\checkmark$ & $\checkmark$ & $\checkmark$ & & $\checkmark$ & & & $\checkmark$ & $\checkmark$ \\
\hline Edinburgh Post-Natal Depression Scale (EPDS) & & $\checkmark$ & & & & & & & \\
\hline Choline Inhibitor Questionnaire & $\checkmark$ & $\checkmark$ & $\checkmark$ & & $\checkmark$ & & & $\checkmark$ & $\checkmark$ \\
\hline Lead Risk Assessment & $\checkmark$ & $\checkmark$ & $\checkmark$ & & $\checkmark$ & & & $\checkmark$ & $\checkmark$ \\
\hline Child Health Update & $\checkmark$ & $\checkmark$ & $\checkmark$ & & $\checkmark$ & & & $\checkmark$ & $\checkmark$ \\
\hline Nutritional Data System for Research (NDSR) & $\checkmark$ & $\checkmark$ & $\checkmark$ & & $\checkmark$ & & & $\checkmark$ & \\
\hline
\end{tabular}

Phone Visit Data collected at $3,6,9,15,18,21,27,30,33,42,48$, and 56 months

\section{Timepoint Details}

\begin{tabular}{|l|l|l|}
\hline Timepoint & Detail & Age \\
\hline M1 & Enrollment Clinic Visit & $16-26$ weeks pregnant \\
\hline M2 & 3rd Trimester Clinic Visit & $27-42$ weeks pregnant \\
\hline M3 & Birth & newborn \\
\hline HV1 & Home Visit & 4 weeks \\
\hline CV1 & Clinic Visit & 12 months \\
\hline CV2 & Clinic Visit & 24 months \\
\hline HV2 & Home Visit & 24 months \\
\hline CV3 & Clinic Visit & 36 months \\
\hline CV4 & Clinic Visit & $48-60$ months \\
\hline
\end{tabular}




\section{B Psychosocial Measures}

We provide a brief overview of on the types of data used in the analysis to capture relevant information about a mother's and child's psychosocial measures.

Knowledge of Infant Development Inventory.

The KIDI assesses a person's familiarity with infant norms and milestones related to infant development up to 24 months, developmental principles and processes, parenting practices and child-rearing strategies, and health care and safety guidelines and practices (MacPhee 1981). The KIDI does not contain subscales but can be grouped into four nonexclusive categories (derived from sampling of the literature on infancy) to obtain more specific information on a person's (1) knowledge on infant norms and milestones, (2) principles of infant development, (3) parenting and (4) health and safety (Veddovi, Kenny, Gibson, Bowen and Starte 2001).

The KIDI is a 58-item inventory. Each item describes what a typical infant might be like or what could affect the infant's growth and behavior. The participant is asked to rate her degree of agreement (agree, disagree, or not sure) on items that describe typical infant behavior, what could affect infant growth or behavior, and the typical age at which infants engage in a particular behavior. Three summary scores are calculated: (1) attempted score $=$ percentage of items attempted (i.e. not answered with "not sure") as a measure of confidence; (2) accuracy score = percentage correct of the attempted answers; and (3) total correct score $=$ percentage correct of all the KIDI items. Possible scores range from 0 to 100.

Household Questionnaire

CANDLE investigators created the Household Questionnaire to assess the number and type of people living with the CANDLE participant and other information about the CANDLE participant's romantic partner and daily life. The Household Questionnaire contains items about the number and type of individuals in the household (and relationship to the 
participant or primary caregiver). In addition, the questionnaire includes questions about the father of the CANDLE child, the CANDLE participant's romantic partner, attendance at religious services, employment, and the CANDLE participant's neighborhood.

Child Abuse Potential Inventory

The CAPI is used to determine a child's risk of being physically abused (Milner and Crouch 2012). The CAPI is a screening tool consisting of 160 statements with which the respondent can agree or disagree. The CAPI contains a 77-item physical abuse scale, six domains of abuse (distress, rigidity, unhappiness, problems with child and self, problems with family, and problems from others), and three validity scales (lie, random response, and inconsistency) that form three response-distortion indexes (faking-good, faking-bad, and random responses) (Milner and Crouch 2012). The validity scales are used to determine whether respondents might be exaggerating or distorting their answers. The CAPI also contains two special scales: ego strength and loneliness. The sums of responses indicative of abuse, distress, rigidity, unhappiness, problems with family, problems with child and self, and problems with others are calculated for each scale, with some responses weighted more heavily than others, as indicated in the CAPI scoring manual (Milner 1986). Scales indicative of ego strength and loneliness are also calculated. Binary cutoff scores indicate whether someone has elevated potential for each of the domains.

Parent-Child Interaction Nursing Child Assessment Satellite Training Teaching Scales

The NCAST PCI Teaching Scales assess how children who might be biologically or environmentally at risk for developmental problems (e.g., low intelligence quotient, language, or attention problems) interact with their parents (Pridham, Lutz, Anderson, Riesch and Becker 2010). Barnard et al. developed the NCAST observational system for children up to 3 years of age, based on an ecological model (Barnard, Eyres, Lobo and Snyder 1983).

The NCAST PCI Teaching Scales, currently referred to as NCAST PCI, is a 73-item yes/no observational measure. The NCAST PCI contains four parent or caregiver behavior 
subscales (sensitivity to cues, response to child's distress, social-emotional growth fostering, and cognitive growth fostering) and two child-specific subscales (clarity of cues and responsiveness to parent) (Sumner and Spietz 1996). Additionally, the NCAST PCI assesses potential disengagement cues (e.g., back arching, choking, coughing, crawling away), length of teaching time, name of task, setting, presence of others, child's birth order, and child's state at beginning of teaching. Total scores are obtained for the mother alone, child alone, and mother and child combined. Subscales for each of the domains and separate contingency scores (items representing responsiveness of interactions) are also calculated. Subscale, contingency scales, and total scores are the sum of the number of items with "yes" responses (Horodynski and Gibbons 2004). The NCAST PCI has established clinically relevant cutoff scores that identify "worrisome" cases. The NCAST database was used to determine the 10th-percentile score distribution obtained by healthy full-term infants and their mothers. Scores higher than the 10th percentile are considered to fall within the normal range. Scores lower than the 10th percentile suggest increased risk for poor mother-child interaction, and dyads scoring below this level could be at risk for a variety of poor outcomes (Sumner and Spietz 1996).

\section{Brief Infant-Toddler Social and Emotional Assessment}

BITSEA was designed to screen infants or toddlers at risk for or currently experiencing social-emotional or behavioral problems (Briggs-Gowan, Carter, Irwin, Wachtel and Cicchetti 2004, Karabekiroglu, Briggs-Gowan, Carter, Rodopman-Arman and Akbas 2010).

The 42-item BITSEA is designed to assess children ages 12 months to 36 months. For each of the 42 items, the mother provides a response that best describes her infant's or toddler's behavior in the last month. BITSEA consists of two multi-item scales: the problem total scale (31 items) and the competence total scale (11 items). The problem total scale consists of three subscales: externalizing problems (six items identifying overactivity, aggression and defiance), internalizing problems (eight items identifying anxiety and depression), and 
dysregulation (eight items identifying negative emotionality and eating and sleeping problems). The competence scale assesses social-emotional abilities such as empathy, prosocial behaviors and compliance (Briggs-Gowan and Carter 2008). 